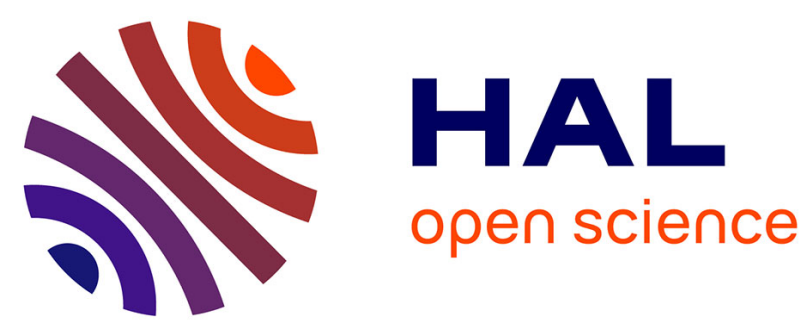

\title{
Dihydrogen to Dihydride Isomerization Mechanism in [(C5Me5)FeH2(Ph2PCH2CH2PPh2)]+ through the Experimental and Theoretical Analysis of Kinetic Isotope Effects
}

Miguel Baya, Olivier Maresca, Rinaldo Poli, Yannick Coppel, Feliu Maseras, Agustí Lledós, Natalia V Belkova, Pavel Dub, Lina M Epstein, Elena S Shubina

\section{- To cite this version:}

Miguel Baya, Olivier Maresca, Rinaldo Poli, Yannick Coppel, Feliu Maseras, et al.. Dihydrogen to Dihydride Isomerization Mechanism in [(C5Me5)FeH2(Ph2PCH2CH2PPh2)]+ through the Experimental and Theoretical Analysis of Kinetic Isotope Effects. Inorganic Chemistry, 2006, 45 (25), pp.10248-10262. 10.1021/ic061428n . hal-03195868

\section{HAL Id: hal-03195868 \\ https://hal.science/hal-03195868}

Submitted on 12 Apr 2021

HAL is a multi-disciplinary open access archive for the deposit and dissemination of scientific research documents, whether they are published or not. The documents may come from teaching and research institutions in France or abroad, or from public or private research centers.
L'archive ouverte pluridisciplinaire HAL, est destinée au dépôt et à la diffusion de documents scientifiques de niveau recherche, publiés ou non, émanant des établissements d'enseignement et de recherche français ou étrangers, des laboratoires publics ou privés. 


\title{
Dihydrogen to Dihydride Isomerization Mechanism in $\left[\left(\mathrm{C}_{5} \mathrm{Me}_{5}\right) \mathrm{FeH}_{2}\left(\mathrm{Ph}_{2} \mathrm{PCH}_{2} \mathrm{CH}_{2} \mathrm{PPh}_{2}\right)\right]^{+}$through the Experimental and Theoretical Analysis of Kinetic Isotope Effects
}

\author{
Miguel Baya, ${ }^{\mathrm{a}, \mathrm{b} \ddagger}$ Olivier Maresca ${ }^{\mathrm{b}}$, Rinaldo Poli, ${ }^{\mathrm{a} *}$ Yannick Coppel, ${ }^{\mathrm{a}}$ Feliu Maseras ${ }^{\mathrm{b} \S}$, Agustí

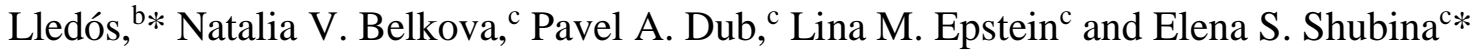

a Laboratoire de Chimie de Coordination, UPR CNRS 8241 liée par convention à l'Université Paul Sabatier et à l'Institut National Polytechnique de Toulouse, 205 Route de Narbonne, 31077 Toulouse Cedex, France

${ }^{\mathrm{b}}$ Departament de Química, Edifici C.n, Universitat Autònoma de Barcelona, 08193 Bellaterra, Catalonia, Spain

${ }^{\mathrm{c}}$ Nesmeyanov Institute of Organoelement Compounds, Russian Academy of Sciences, Vavilov Street 28, 119991 Moscow, Russia

$\$$ Current address: Departamento de Química Inorgánica, Instituto de Ciencia de Materiales de Aragón, Universidad de Zaragoza-CSIC, 50009 Zaragoza, Spain.

${ }^{\S}$ Current address: Institute of Chemical Research of Catalonia (ICIQ), 43007 Tarragona, Catalonia, Spain.

Corresponding author: Rinaldo Poli, fax: +33-561553003, poli@lcc-toulouse.fr 


\section{Abstract}

The isomerization of complex $\left[\mathrm{Cp} * \mathrm{Fe}(\mathrm{dppe})\left(\eta^{2}-\mathrm{H}_{2}\right)\right]^{+}$, generated in situ by low temperature protonation of $\mathrm{Cp} * \mathrm{Fe}(\mathrm{dppe}) \mathrm{H}$ with either $\mathrm{HBF}_{4}$ or $\mathrm{CF}_{3} \mathrm{COOH}$, to the dihydride tautomer trans$\left[\mathrm{Cp} * \mathrm{Fe}(\mathrm{dppe})(\mathrm{H})_{2}\right]^{+}$is irreversible and follows first order kinetics in the -10 to $+15^{\circ} \mathrm{C}$ range with $\Delta \mathrm{H}^{\ddagger}=21.6 \pm 0.8 \mathrm{kcal} \mathrm{mol}^{-1}$ and $\Delta \mathrm{S}^{\ddagger}=5 \pm 3$ e.u. The isomerization rate constant is essentially independent of the nature and quantity of strong acid. DFT calculations on various models, including the complete system at both the $\mathrm{QM} / \mathrm{MM}$ and full $\mathrm{QM}$ levels, probe the relative importance of steric and electronic effects for the relative stability of the non-classical and classical isomers and identify two likely isomerization mechanisms: a "direct" pathway involving simultaneous H-H bond breaking and cis-trans isomerization and a "via Cp" pathway involving agostic $\mathrm{C}_{5} \mathrm{Me}_{5} \mathrm{H}$ intermediates. Both pathways are characterized by activation energies in close correspondence with the experimental value (21.3 and $22.2 \mathrm{kcal} \mathrm{mol}^{-1}$ respectively). Further kinetic studies were carried out for the $\mathrm{Cp} * \mathrm{Fe}($ dppe $) \mathrm{H}+\mathrm{CF}_{3} \mathrm{COOD}$ and $\mathrm{Cp} * \mathrm{Fe}(\mathrm{dppe}) \mathrm{D}+$ $\mathrm{CF}_{3} \mathrm{COOD}$ systems at $273 \mathrm{~K}$. The $\left[\mathrm{Cp} * \mathrm{Fe}(\mathrm{dppe})\left(\eta^{2}-\mathrm{HD}\right)\right]^{+}$complex establishes a very rapid isotope redistribution equilibrium with the $\left(\eta^{2}-\mathrm{H}_{2}\right)$ and $\left(\eta^{2}-\mathrm{D}_{2}\right)$ analogues. The equilibrium constant value $(K=3.3 \pm 0.3)$ indicates a significant equilibrium isotope effect (EIE). Simulation of the rate data provides access to the individual isomerization rate constants $k_{\mathrm{HH}}, k_{\mathrm{HD}}$ and $k_{\mathrm{DD}}$ for the three isotopomers, yielding kinetic isotope effects (KIE): $k_{\mathrm{HH}} / k_{\mathrm{HD}}=1.24 \pm 0.01$ and $k_{\mathrm{HD}} / k_{\mathrm{DD}}=$ $1.58 \pm 0.01$ (and consequently $k_{\mathrm{HH}} / k_{\mathrm{DD}}=1.96 \pm 0.02$ ). The analysis of the DFT calculated frequencies, using the $\left[\mathrm{Cp} * \mathrm{Fe}(\mathrm{dhpe}) \mathrm{H}_{2}\right]^{+}$model system, for the $\left[\mathrm{Cp} * \mathrm{Fe}(\mathrm{dhpe})\left(\eta^{2}-\mathrm{XY}\right)\right]^{+}$ isotopomers as well as transition states for the "direct" (TS $\mathbf{T d i r}_{\text {) }}$ and "via Cp" (TSrot) pathways (X $=\mathrm{H}, \mathrm{D})$ allowed the computation of the expected isotope effects. Comparison with the experiment strongly suggests that the mechanism occurs via the "direct" pathway for the present system, although the small difference in calculated energy barriers suggests that the "via Cp" pathway may be preferred in other cases. 


\section{Introduction}

It is nowadays well established that most 16-electron $L_{n} M$ fragments form a dihydrogen complex $\mathrm{L}_{n} \mathrm{M}\left(\eta^{2}-\mathrm{H}_{2}\right)$ in the initial stages of their interaction with $\mathrm{H}_{2} .{ }^{1}$ Subsequently, depending on the properties of the metal and the ligands, an oxidative addition process may take place leading to a dihydride, or the dihydrogen complex may remain as the stable final product. An equilibrium between the two isomeric forms may also be observed. Dihydrogen complexes are also sometimes obtained by protonating hydride precursors under kinetically controlled conditions, preceding in some cases the rearrangement to the thermodynamic classical dihydride product. $^{2-7}$ For the Group 8 half-sandwich systems such as $\left[\mathrm{CpRuLL}^{\prime} \mathrm{H}_{2}\right]^{+}(\mathrm{L}=$ tertiary phosphine $)^{3,4}$ and $\mathrm{Fe}$ analogues, ${ }^{6,7}$ this interconversion implies an important stereochemical change. In these systems two different mutual arrangements of two ligands are possible: cisoid and transoid. As there are no reports of the coexistence of dihydrogen and cis-dihydride isomers, the interconversion must entail passing from the three-legged piano stool dihydrogen complex to a transoid square-based four-legged piano stool dihydride (Scheme 1). ${ }^{8}$ Thus, the cleavage of the $\mathrm{H}-\mathrm{H}$ bond is accompanied by a cis-trans rearrangement which involves the migration of one $\mathrm{H}$ atom from one side of the molecule to the opposite one. The isomerization of the dihydrogen complex $\left[\mathrm{Cp} * \mathrm{Fe}(\mathrm{dppe})\left(\eta^{2}-\mathrm{H}_{2}\right)\right]^{+}$is particularly interesting, since the chelate nature of the diphosphine ligand may impose an extra obstacle to the $\mathrm{H}$ migration to yield the observed trans structure for the dihydride product.
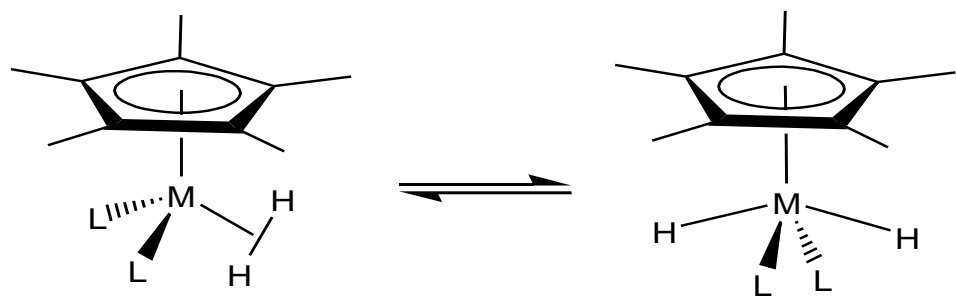

Scheme 1

The isomerization kinetics have been studied by NMR spectroscopy for the cationic ruthenium dihydrogen complexes. ${ }^{3,9}$ Reported activation enthalpies range from 16 to 21 
$\mathrm{kcal} / \mathrm{mol}$, with small and negative activation entropies. The highest values have been obtained for bidentate phosphines with sterically demanding ligands. ${ }^{9}$ The small $\Delta S^{\ddagger}$ supports an intramolecular mechanism in which the $\mathrm{H}_{2}$ ligand has lost rotational freedom in the transition state. ${ }^{3}$ A dissociative mechanism has been proposed when bulky and good electron donor ligands are present, ${ }^{9}$ but was discarded for simpler system on the basis of kinetic evidence (no retardation effect was observed in the presence of excess ligand). ${ }^{3}$ The possibility of an intermolecular deprotonation followed by re-protonation of the neutral hydride intermediate was ruled out for the ruthenium system on the basis of the absence of isotope scrambling for a selectively generated (HD) system. ${ }^{3,9}$ Finally, an alternative intramolecular mechanism proceeding by transfer of a $\mathrm{H}$ atom from the $\mathrm{H}_{2}$ ligand to the cyclopentadienyl ligand, thereby affording an intermediate cyclopentadiene complex, followed by ring rotation and transfer back to the metal center, has also been contemplated but discarded on the basis of indirect bond energy arguments. ${ }^{3}$ A theoretical study of this isomerization process has not been tackled yet, and no reports on transition states or comparison of energy barriers for different mechanisms can be found.

We have recently reported experimental investigations, including a stopped-flow kinetic study, of the hydrogen bonding and proton transfer to $\mathrm{Cp} * \mathrm{Fe}(\mathrm{dppe}) \mathrm{H}$ with a variety of proton donors (HA) of different acid strength. ${ }^{10,11}$ This study has highlighted the presence of a hydrogen bonded intermediate involving the hydride site (and not the metal site), $\mathrm{Cp} * \mathrm{Fe}(\mathrm{dppe}) \mathrm{H} \cdots \mathrm{HA}$, the reversibility of the proton transfer step (see Scheme 2), and the need of a second proton donor molecule to trigger the proton transfer process. An accompanying theoretical investigation has mostly focused on the first step, i.e. proton transfer to the hydride ligand. ${ }^{11}$ Concerning the subsequent isomerization process, an intramolecular mechanism is suggested by an identical rate when using proton donors of different strength at the same temperature. The alternative reversible deprotonation, followed by a slower protonation at the metal site, is inconsistent with this experimental observation. ${ }^{10}$ Our attempts to carry out an Eyring analysis of this isomerization step were complicated by the reversibility of the preceding proton transfer step, which resulted in strong coupling between two key rate constants in the mathematical fitting procedure, the first rate constant leading from the dihydrogen intermediate to the final dihydride product ( $k_{2}$, irreversible step), the second one leading from the same intermediate back to the starting monohydride complex $\left(k_{-1}\right.$, see Supporting Information of ref. $\left.{ }^{11}\right)$. 


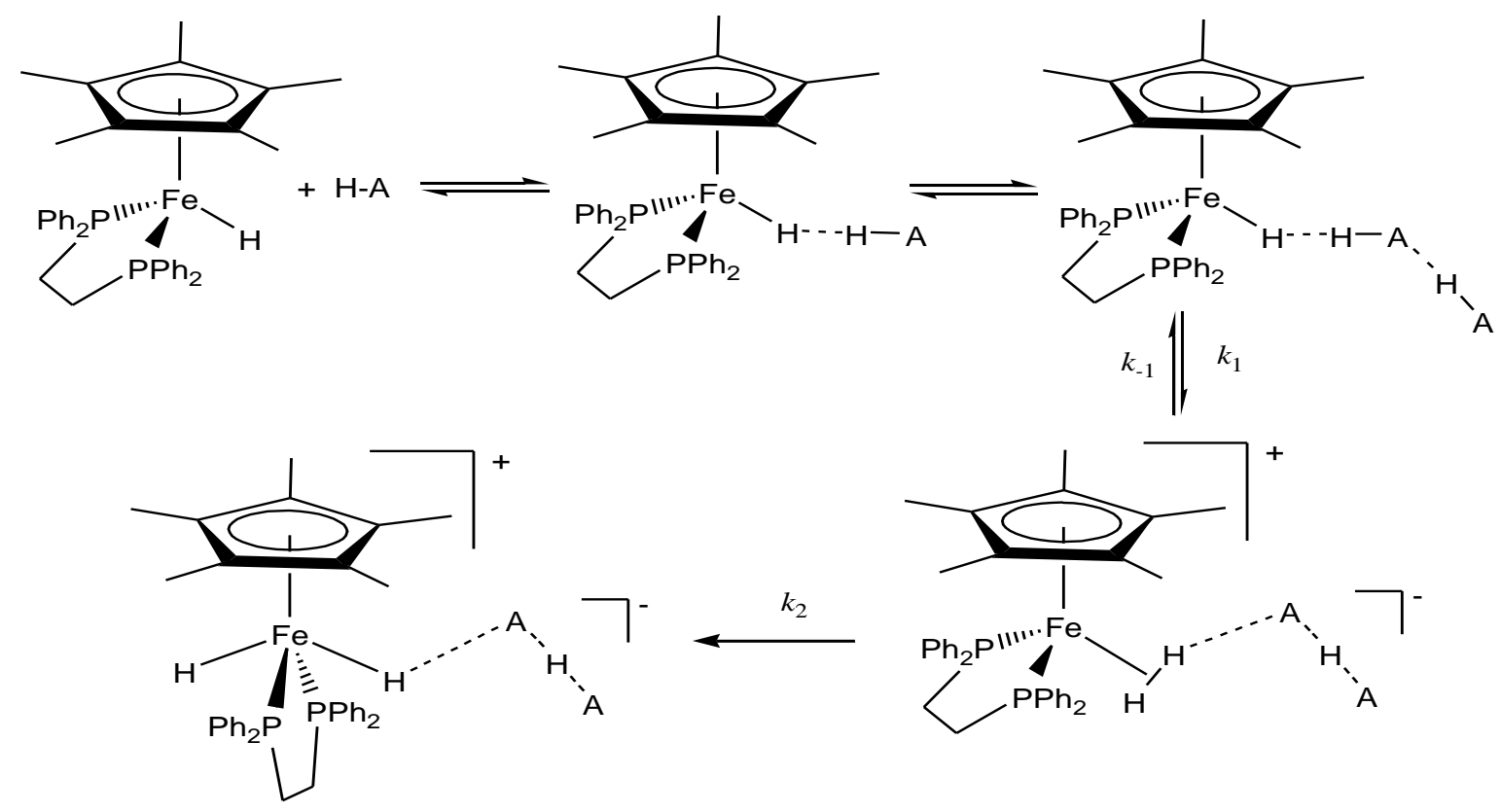

Scheme 2

In this report, we present a new experimental study that has led to the determination of the accurate rate constant and activation parameters for the isomerization process of the $\left[\mathrm{Cp} * \mathrm{Fe} \text { (dppe) } \mathrm{H}_{2}\right]^{+}$system when the counterion is either $\mathrm{BF}_{4}^{-}$or $\mathrm{CF}_{3} \mathrm{COO}^{-}$. These investigations include the determination of the kinetic isotope effects $k_{\mathrm{HH}} / k_{\mathrm{HD}}$ and $k_{\mathrm{HD}} / k_{\mathrm{DD}}$, obtained from the comparative isomerization rates of complexes $\left[\mathrm{Cp} * \mathrm{Fe}(\mathrm{dppe})\left(\mathrm{H}_{2}\right)\right]^{+}\left(k_{\mathrm{HH}}\right),[\mathrm{Cp} * \mathrm{Fe}(\mathrm{dppe})(\mathrm{HD})]^{+}$ $\left(k_{\mathrm{HD}}\right)$, and $\left[\mathrm{Cp} * \mathrm{Fe}(\mathrm{dppe})\left(\mathrm{D}_{2}\right)\right]^{+}\left(k_{\mathrm{DD}}\right)$. To the best of our knowledge, the experimental determination of isotope effects for the transformation of a nonclassical $\left[\left(\mathrm{H}_{2}\right) /(\mathrm{HD}) /\left(\mathrm{D}_{2}\right)\right]$ to classical $\left[(H)_{2} /(H)(D) /(D)_{2}\right]$ dihydride complex is unprecedented. This is accompanied by a theoretical investigation, whose purpose is twofold. Firstly, it seeks to determine the subtle factors tuning the relative stability between the non-classical dihydrogen and the classical dihydride isomers of the $\left[\left(\mathrm{C}_{5} \mathrm{R}_{5}\right) \mathrm{Fe}\left(\mathrm{R}_{2}{ }_{2} \mathrm{PCH}_{2} \mathrm{CH}_{2} \mathrm{PR}_{2}{ }_{2}\right) \mathrm{H}_{2}\right]^{+}$complexes $\left(\mathrm{R}=\mathrm{H}, \mathrm{Me} ; \mathrm{R}{ }^{\prime}=\mathrm{H}, \mathrm{Ph}, i\right.$ Pr), separating electronic and steric contributions. Secondly, it explores the intimate details of the possible intramolecular isomerization mechanisms. In particular, the discrimination between two pathways showing very similar computed activation barriers (both close to the experimental value) will be possible through the analysis of the kinetic isotope effects. The computational 
work involves pure Quantum Mechanics and mixed Quantum Mechanics / Molecular Mechanics methods.

\section{Experimental Part}

All manipulations were carried out under an argon atmosphere by standard Schlenk techniques. Complexes $\mathrm{Cp} * \mathrm{Fe}(\mathrm{dppe}) \mathrm{H}$ and $\mathrm{Cp} * \mathrm{Fe}(\mathrm{dppe}) \mathrm{D}$ were synthesized according to the literature. ${ }^{7}$ NMR characterization of the deuteride complex in $\mathrm{C}_{6} \mathrm{D}_{6}:{ }^{2} \mathrm{H} \mathrm{NMR}, \delta-16.9\left(\mathrm{t}, \mathrm{J}_{\mathrm{PD}}=\right.$ $10.4 \mathrm{~Hz}) ;{ }^{31} \mathrm{P}\left\{{ }^{1} \mathrm{H}\right\}, \delta 111.5\left(\mathrm{t}, \mathrm{J}_{\mathrm{PD}}=10.3 \mathrm{~Hz}\right)$. In addition, the ${ }^{1} \mathrm{H}$ NMR spectrum shows contamination by the hydride complex, $\mathrm{Cp} * \mathrm{Fe}(\mathrm{dppe}) \mathrm{H}(25 \%$, by integration of the hydride resonance against the $\mathrm{Cp}^{*}$ resonance). The acids $\mathrm{HBF}_{4} \cdot \mathrm{OEt}_{2}, \mathrm{CF}_{3} \mathrm{COOH}$ and $\mathrm{CF}_{3} \mathrm{COOD}$ were purchased from Aldrich and used as received.

The NMR studies were carried out in standard $5 \mathrm{~mm}-\mathrm{NMR}$ tubes containing solutions of the complexes in $\mathrm{CD}_{2} \mathrm{Cl}_{2}$. The ${ }^{1} \mathrm{H}$ and ${ }^{31} \mathrm{P}$ NMR data were collected with a Bruker AMX 400 spectrometer operating at 400.13 and $161.98 \mathrm{MHz}$ respectively. The low temperature kinetics experiments with ${ }^{31} \mathrm{P} \operatorname{NMR}\left\{{ }^{1} \mathrm{H},{ }^{2} \mathrm{H}\right\}$ monitoring were carried out on a Bruker AV500 spectrometer equipped with a $5 \mathrm{~mm}$ triple resonance inverse probe with dedicated ${ }^{31} \mathrm{P}$ channel operating at $500.33 \mathrm{MHz}$ for ${ }^{1} \mathrm{H}, 202.54 \mathrm{MHz}$ for ${ }^{31} \mathrm{P}$, and $76.80 \mathrm{MHz}$ for ${ }^{2} \mathrm{H}$. For the purpose of quantitative concentration measurements for the kinetics runs, the ${ }^{31} \mathrm{P}$ NMR spectra were recorded with inverse gated ${ }^{1} \mathrm{H}$ and ${ }^{2} \mathrm{H}$ decoupling. For ${ }^{31} \mathrm{P}$ and ${ }^{1} \mathrm{H} \mathrm{NMR}$, a typical pulse width corresponding to a $30^{\circ}$ flip angle and $30 \mathrm{~s}$ relaxation delays were used to obtain reliable integration data. In case of overlapping resonances, the quantitative evaluation was realized by peak deconvolution (see Supporting Information). All chemical shifts for ${ }^{1} \mathrm{H}$ and ${ }^{2} \mathrm{H}$ are relative to TMS using residual peak of the solvent as a secondary standard. ${ }^{31} \mathrm{P}$ chemical shifts were referenced to an external $85 \% \mathrm{H}_{3} \mathrm{PO}_{4}$ sample. The temperature was regulated with a TV-3000 Bruker unit. Temperature calibration was determined using a methanol chemical shift thermometer. The temperature accuracy and stability was $\pm 1 \mathrm{~K}$. All mixings between the acid and the hydride complexes were performed at $-80^{\circ} \mathrm{C}$. 


\section{Computational Details}

Quantum mechanical calculations were performed with the Gaussian98 package $^{12}$ at the DFT B3PW91 level. ${ }^{13-15}$ Furthermore, coupled cluster $^{16,17}$ single-point calculations on the DFT optimized structures, using both single and double substitutions ${ }^{18-21}$ and including triple excitations non-iteratively, ${ }^{22}$ were performed in order to obtain more reliable energies. Core electrons of the $\mathrm{Fe}$ and of the $\mathrm{P}$ atoms were described using the effective core pseudopotentials of Hay-Wadt ${ }^{23,} 24$ and valence electrons were described with the standard LANL2DZ basis set associated to the ECP. ${ }^{12}$ In the case of the $\mathrm{P}$ atoms, a set of $\mathrm{d}$ type functions was added. ${ }^{25}$ Carbon and hydrogen atoms non-bonded to the metal were described with a 6-31G basis set. ${ }^{26}$ The two hydrogen atoms bonded to the $\mathrm{Fe}$ atom were described with a $6-31 \mathrm{G}(\mathrm{d}, \mathrm{p})$ set of basis functions. ${ }^{27}$

Mixed Quantum Mechanics / Molecular Mechanics (QM/MM) calculations were performed with the IMOMM method ${ }^{28}$ with a program built from modified versions of two standard programs: Gaussian $98^{12}$ for the quantum part (QM) and $\mathrm{mm} 3(92)^{29}$ for the molecular mechanics calculations (MM). The IMOMM approach will be used to point out the effect of the substituents located both on the $\mathrm{Cp}$ group and on the phosphine ligand. The substituents are methyl, phenyl and isopropyl groups treated in the MM part through the MM3 force field. The same basis set as in the pure quantum computations was used at the same level of theory for the quantum part. In the IMOMM computations all of the geometrical parameters were optimized except for the distances between the atoms linking the QM and MM parts. The kinetic isotope effects were calculated as described in the Results and Discussion section using harmonic vibrational frequencies obtained from frequency calculations. The frequencies of each isotopically substituted system were obtained at the fixed geometry previously optimized for the corresponding unsubstituted isotopomer. These calculations were carried out with Gaussian03. ${ }^{30}$ Solvent effects were taken into account by means of polarized continuum model (PCM) calculations $^{31,32}$ using standard options. ${ }^{30}$ Individual solvation cavity were added on the hydrogen atoms directly bonded to the Fe atom. The free energies of solvation were computed in dichloromethane $(\varepsilon=8.93)$ at the geometries optimized in gas phase. 


\section{Results and Discussion}

\section{Isomerization kinetics of $\left[\mathrm{Cp}^{*} \mathrm{Fe}(\mathrm{dppe})\left(\eta^{2}-\mathrm{X}_{2}\right)\right]^{+}(\mathrm{X}=\mathrm{H}, \mathrm{D})$.}

As outlined in the introduction, the accurate determination of the isomerization rate constant for the process shown in Scheme 2 at different temperatures was thwarted by the reversibility of the proton transfer step when a mildly acidic proton donor (i.e. $\left(\mathrm{CF}_{3}\right)_{\mathrm{n}} \mathrm{CH}_{3-\mathrm{n}} \mathrm{OH}$ with $\mathrm{n}=1,2,3$ ) was used. In an attempt to circumvent this problem, we have carried out stopped-flow studies using stronger acids $\left(\mathrm{CF}_{3} \mathrm{COOH}, \mathrm{HBF}_{4}\right)$, in order to force the proton transfer step to quantitative conversion and then measure the subsequent isomerization under clean pseudo-first order conditions. Unfortunately, these experimental conditions introduce another complication. The final dihydride product is unstable in dichloromethane in the presence of an excess of strong acids, leading to the oxidized chloride complex $\left[\mathrm{Cp}^{*} \mathrm{Fe}(\mathrm{dppe}) \mathrm{Cl}\right]^{+}$, as described previously. ${ }^{10}$ This phenomenon is not observed when using the $\left(\mathrm{CF}_{3}\right)_{\mathrm{n}} \mathrm{CH}_{3-\mathrm{n}} \mathrm{OH}$ proton donors, even in large excess amounts, whereas it is observed when using $\mathrm{CF}_{3} \mathrm{COOH}$ or $\mathrm{HBF}_{4}$ in greater than a twofold excess. Thus, the system is not amenable to a clean kinetic study in dichloromethane. A change of solvent has been envisaged, but no ideal system has so far been found: THF reduces considerably the thermodynamic drive to proton transfer (because of the free acid stabilization by hydrogen bonding with the solvent molecules) and polymerizes under strongly acidic conditions; toluene cannot keep the produced salts in solution at sufficient concentrations.

A convenient solution to this problem was found by recurring to the NMR technique. The advantage in this case is that the relative amounts of dihydrogen and dihydride complexes can be measured directly and independently, even in the presence of any amount of the $[\mathrm{Cp} * \mathrm{Fe}(\mathrm{dppe}) \mathrm{Cl}]^{+}$decomposition product (a paramagnetic complex). Therefore, the rate at

which the intermediate dihydrogen complex decays is directly accessible with accuracy. In addition, working at low temperatures (thereby slowing down the isomerization process to a suitable timescale for NMR monitoring) reduces the impact of the acid-catalyzed decomposition in dichlormethane. The sum of the integrated intensities for the dihydrogen and dihydride complexes, monitored against that of an internal standard, provide a direct gauge of the system stability. 
After generating the intermediate dihydrogen complex quantitatively in situ by low temperature $\left(-80^{\circ} \mathrm{C}\right)$ addition of the appropriate amount of strong acid (see Table 1 for details), the monitoring was carried out at four different temperatures $\left(-10,0,5\right.$ and $15^{\circ} \mathrm{C}$, runs $\left.1-4\right)$. Both the decay of the dihydrogen complex resonance (examples are shown in Figure 1, top) and the growth of the final dihydride complex resonance were monitored by ${ }^{1} \mathrm{H}$ NMR spectroscopy. The sum of the integral, after normalization relative to the solvent peak which was used as an internal standard, was relatively constant throughout the reaction, showing limited decomposition ( $<10 \%$ when using 1 equivalent of strong acid; a maximum $17 \%$ decomposition during 153 min was found for run 5 where a greater excess of acid was used). However, since the acid-catalyzed decomposition occurs only for the classical product and since the isomerization is irreversible, ${ }^{10}$ the decay rate of the nonclassical reagent is an accurate measure of the isomerization rate.

The nonclassical resonance decay gives an excellent fit to the first order rate law at each temperature (examples are shown in Figure 1, right), yielding the rate constants $k_{\mathrm{HH}}$ reported in Table 1. The three different kinetic runs carried out at $0^{\circ} \mathrm{C}$ (runs 2,5 and 6) show that the isomerization rate does not significantly depend on the acid concentration (compare runs 2 and 5), nor on its nature (compare runs 2 and 6). The latter observation confirms our previous findings of identical isomerization rates using different $\left(\mathrm{CF}_{3}\right)_{\mathrm{n}} \mathrm{CH}_{3-\mathrm{n}} \mathrm{OH}$ proton donors. ${ }^{10}$ Comparison of runs 6 and 7, on the other hand, shows a significant kinetic isotope effect (KIE). The monitoring of run 7 could not be carried out conveniently by ${ }^{1} \mathrm{H} \mathrm{NMR}$, since the $\mathrm{Cp}^{*}$ and dppe peaks of reactant and product are not significantly spread apart. The quantitative determination was based on the integration of the inverse-gated doubly decoupled $\left\{{ }^{1} \mathrm{H},{ }^{2} \mathrm{H}\right\}{ }^{31} \mathrm{P}$ NMR resonance (see Experimental part). It should be remarked that the ca. $25 \%$ of the $\mathrm{Cp} * \mathrm{FeH}(\mathrm{dppe})$ isotopomer in the deuteride starting material may slightly affect the resulting rate constant value, given that the ${ }^{1} \mathrm{H}$-containing nonclassical impurity, $\left[\mathrm{Cp} * \mathrm{Fe}\left(\eta^{2}-\mathrm{HD}\right)(\mathrm{dppe})\right]^{+}$, isomerizes faster (vide infra). Therefore, the value of $k_{\mathrm{DD}}$ reported in Table 1 should be considered as an upper estimate of the isomerization rate constant for complex $\left[\mathrm{Cp} * \mathrm{Fe}(\mathrm{dppe})\left(\eta^{2}-\right.\right.$ $\left.\left.\mathrm{D}_{2}\right)\right]^{+}$(a more accurate value for $k_{\mathrm{DD}}$ is available from an alternative approach, vide infra). The Eyring analysis of the rate constants $k_{\mathrm{HH}}$ of runs 1-4 (Figure 2) yields the activation parameters $\Delta \mathrm{H}^{\dagger}=21.6 \pm 0.8 \mathrm{kcal} \mathrm{mol}^{-1}$ and $\Delta \mathrm{S}^{\dagger}=5 \pm 3$ e.u. These values are similar to those previously reported for related ruthenium derivatives. ${ }^{3,9}$ The enthalpy value resulting from this analysis is 
useful for comparison with the computed energies for the transition states of different potential rearrangement pathways (vide infra).
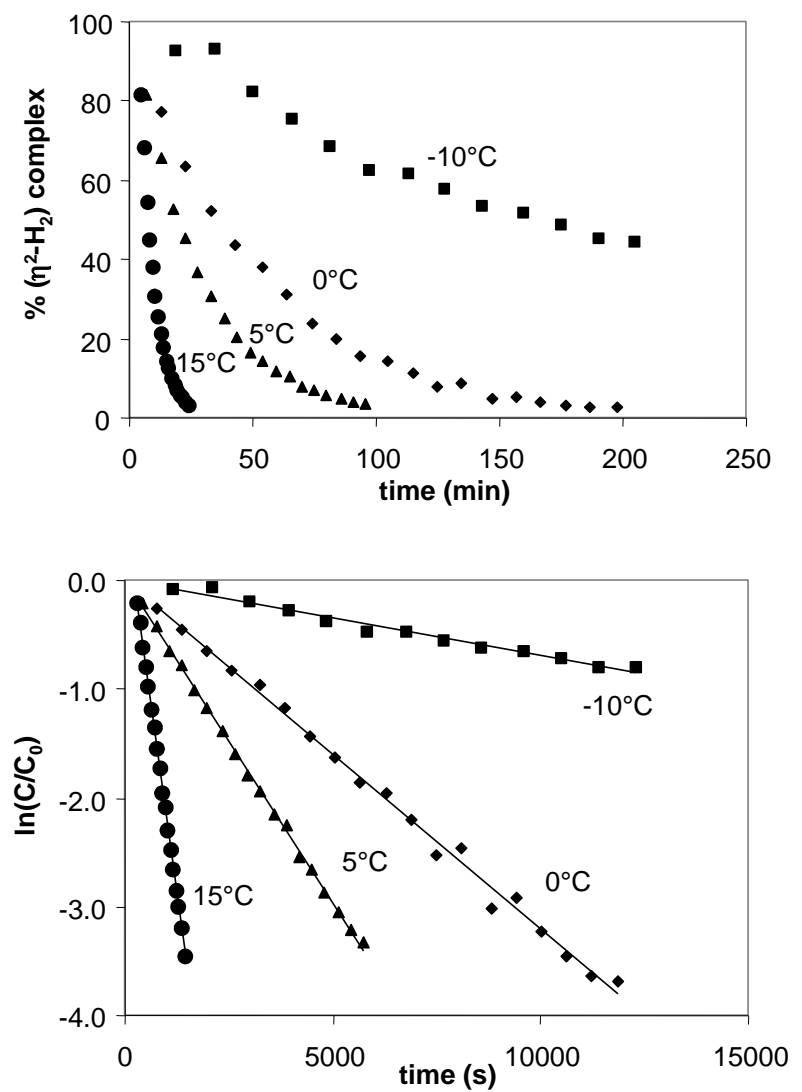

Figure 1. ${ }^{1} \mathrm{H}$ NMR monitoring of the $\left[\mathrm{Cp} * \mathrm{Fe}(\mathrm{dppe})\left(\eta^{2}-\mathrm{H}_{2}\right)\right]^{+}$resonance decay $\left(\mathrm{BF}_{4}^{-}\right.$salt in $\mathrm{CD}_{2} \mathrm{Cl}_{2}$ ).

Table 1. Results of the isomerization kinetics of $\left[\mathrm{Cp} * \mathrm{Fe}(\mathrm{dppe})\left(\eta^{2}-\mathrm{X}_{2}\right)\right]^{+}$to $\left[\mathrm{Cp} * \mathrm{Fe}(\mathrm{dppe})(\mathrm{X})_{2}\right]^{+}(\mathrm{X}=\mathrm{H}, \mathrm{D})$.

\begin{tabular}{|c|c|c|c|c|c|c|c|}
\hline Run & Complex & Acid & {$[\mathrm{HA} / \mathrm{Fe}]$} & $\mathrm{T}\left({ }^{\circ} \mathrm{C}\right)$ & $10^{4} \cdot k_{\mathrm{HH}}\left(\mathrm{s}^{-1}\right)^{\mathrm{a}}$ & $\begin{array}{c}10^{4} \cdot k_{\mathrm{HD}}\left(\mathrm{s}^{-}\right. \\
\left.{ }^{1}\right)^{\mathrm{a}}\end{array}$ & $\begin{array}{c}10^{4} \cdot k_{\mathrm{DD}}(\mathrm{s} \\
1)^{\mathrm{a}}\end{array}$ \\
\hline 1 & $\mathrm{Cp} * \mathrm{Fe}(\mathrm{dppe}) \mathrm{H}$ & $\mathrm{HBF}_{4}$ & 1 & -10 & $0.70 \pm 0.09$ & & \\
\hline 2 & $\mathrm{Cp} * \mathrm{Fe}(\mathrm{dppe}) \mathrm{H}$ & $\mathrm{HBF}_{4}$ & 1 & 0 & $3.21 \pm 0.07$ & & \\
\hline 3 & $\mathrm{Cp} * \mathrm{Fe}(\mathrm{dppe}) \mathrm{H}$ & $\mathrm{HBF}_{4}$ & 1 & 5 & $5.92 \pm 0.15$ & & \\
\hline 4 & $\mathrm{Cp} * \mathrm{Fe}(\mathrm{dppe}) \mathrm{H}$ & $\mathrm{HBF}_{4}$ & 1 & 15 & $28.3 \pm 0.7$ & & \\
\hline 5 & $\mathrm{Cp} * \mathrm{Fe}(\mathrm{dppe}) \mathrm{H}$ & $\mathrm{HBF}_{4}$ & 3 & 0 & $3.53 \pm 0.22$ & & \\
\hline
\end{tabular}




\begin{tabular}{|c|c|c|c|c|c|c|}
\hline $\mathrm{Cp} * \mathrm{Fe}(\mathrm{dppe}) \mathrm{H}$ & $\mathrm{CF}_{3} \mathrm{COOH}$ & 1 & 0 & $3.10 \pm 0.12$ & & \\
\hline $\mathrm{Cp} \mathrm{p}^{*} \mathrm{Fe}(\mathrm{dppe}) \mathrm{D}^{\mathrm{a}}$ & $\mathrm{CF}_{3} \mathrm{COOD}$ & 1 & 0 & & & $1.73 \pm 0.12$ \\
\hline $\mathrm{Cp}{ }^{*} \mathrm{Fe}(\mathrm{dppe}) \mathrm{H}$ & $\mathrm{CF}_{3} \mathrm{COOD}$ & 1 & 0 & $3.07 \pm 0.02$ & $2.48 \pm 0.01$ & $1.56 \pm 0.01$ \\
\hline
\end{tabular}

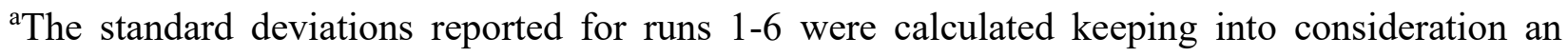
estimated $10 \%$ error in the NMR integration. For run 7 , see Supporting Information. ${ }^{\mathrm{b}}$ The starting material was contaminated by ca. $25 \%$ of $\mathrm{CpFe}(\mathrm{dppe}) \mathrm{H}$.

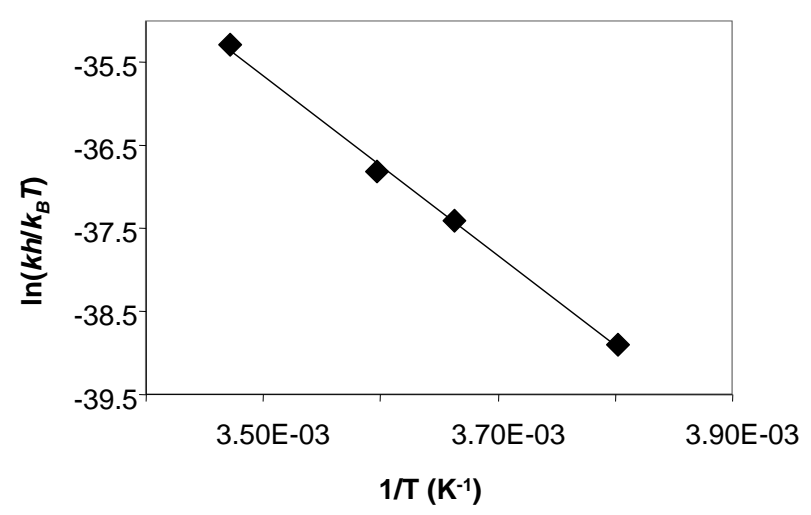

Figure 2. Eyring analysis of the isomerization rate constant $k_{\mathrm{HH}}$.

\section{Role of the Electronic and Steric Effects in the Relative Stabilities of the Dihydrogen and Dihydride Complexes.}

Before analyzing the possible rearrangement pathways in detail from the computational point of view, it is important to gain a full appreciation of the model effect on the relative energies. As a general trend in computational chemistry, models are used to represent the real molecular systems. This is mainly done in order to deal with affordable computation time and system resources, but this procedure also allows to introduce the complexity of the real systems in a gradual way, analyzing at each step the changes suffered by the system. This approach will be used to separate electronic and steric contributions to the relative stabilities of the dihydrogen and dihydride forms. Usually, the system is simplified by replacing substituents with $\mathrm{H}$ atoms. If we apply this general procedure to the $\left[\left(\mathrm{C}_{5} \mathrm{R}_{5}\right) \mathrm{Fe}\left(\mathrm{R}_{2}{ }_{2} \mathrm{PCH}_{2} \mathrm{CH}_{2} \mathrm{PR}_{2}\right) \mathrm{H}_{2}\right]^{+}$complexes, we can define four models as depicted in Scheme 3, together with the real complexes. The smallest model is the $\left[\mathrm{CpFe}(\text { dhpe }) \mathrm{H}_{2}\right]^{+}$complex 1 (dhpe $\left.=\mathrm{PH}_{2}-\mathrm{CH}_{2}-\mathrm{CH}_{2}-\mathrm{PH}_{2}\right)$, where both the methyl groups of the 
$\mathrm{Cp}^{*}$ ligand and the phenyl or isopropyl substituents of the phosphine ligand are replaced by hydrogen atoms. In the second model $\left[\mathrm{Cp} * \mathrm{Fe}(\mathrm{dhpe}) \mathrm{H}_{2}\right]^{+} \mathbf{2}$, only the phosphine substituents are replaced by hydrogen atoms, keeping the whole $\mathrm{Cp}^{*}$. Two additional models can be generated by introducing the real phosphine substituents while keeping the model $\mathrm{Cp}$ ligand: $\left[\mathrm{CpFe}(\mathrm{dppe}) \mathrm{H}_{2}\right]^{+}(\mathbf{3})$ for $\mathrm{R}^{\prime}=\mathrm{Ph}$ and $\left[\mathrm{CpFe}(\text { dippe }) \mathrm{H}_{2}\right]^{+}(\mathbf{5})$ for $\mathrm{R}^{\prime}=i \mathrm{Pr}$. The four models can be related to the two experimentally reported complexes $\left[\mathrm{Cp} * \mathrm{Fe}(\mathrm{dppe}) \mathrm{H}_{2}\right]^{+} \quad(4)^{6}, 33$ and $\left[\mathrm{Cp} * \mathrm{Fe} \text { (dippe) } \mathrm{H}_{2}\right]^{+}(\mathbf{6}){ }^{34}$ The dihydride form of all the species considered in the calculations and the numbering scheme are presented in Scheme 3. The cisoid (dihydrogen) and transoid (dihydride) isomers will be labelled $\mathbf{c}$ and $\mathbf{t}$, respectively.
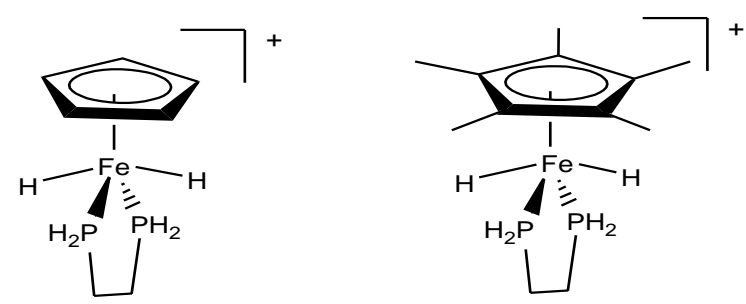

$\mathbf{1}\left[\mathrm{CpFe}(\mathrm{dhpe})(\mathrm{H})_{2}\right]^{+}$

$$
2\left[\mathrm{Cp} * \mathrm{Fe}(\text { dhpe })(\mathrm{H})_{2}\right]^{+}
$$
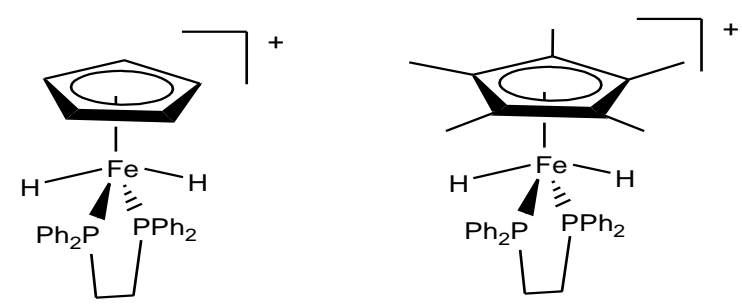

$3\left[\mathrm{CpFe}(\mathrm{dppe})(\mathrm{H})_{2}\right]^{+}$

$4\left[\mathrm{Cp}^{*} \mathrm{Fe}(\mathrm{dppe})(\mathrm{H})_{2}\right]^{+}$
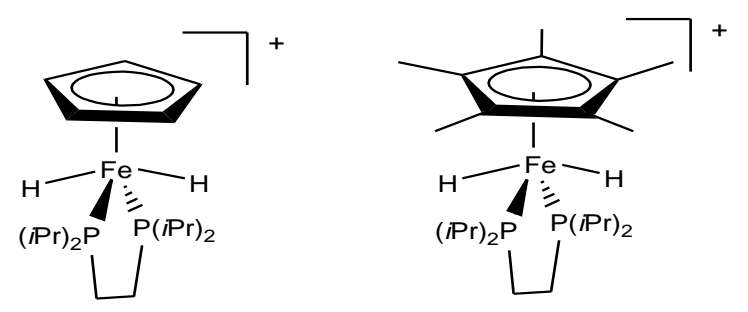

$5\left[\mathrm{CpFe}(\text { dippe })(\mathrm{H})_{2}\right]^{+}$

$6\left[\mathrm{Cp} * \mathrm{Fe}(\text { dippe })(\mathrm{H})_{2}\right]^{+}$

\section{Scheme 3}


The optimized structures of the isomers for the model complex $\mathbf{1}$ are depicted in Figure 3. The structural features of the dihydrogen and dihydride isomers for the systems 1-6 are analyzed in detail in the Supporting Information. The relative energies of the dihydrides 1t-6t with respect to the corresponding dihydrogen isomers 1c-6c are given in Table 2. Our computed values for $\mathbf{1}$ and $4(+6.6$ and $-3.9 \mathrm{kcal} / \mathrm{mol}$, respectively) compare well with those previously reported using a different functional $\left(+4.3\right.$ and $-4.4 \mathrm{kcal} / \mathrm{mol}$, respectively). ${ }^{6}$ To check the accuracy of our methodology we have recalculated the energy of the dihydrogen/dihydride couple of the smallest system 1 with the highly correlated $\operatorname{CCSD}(\mathrm{T})$ method. There is a reasonable agreement between both methods, since the dihydride lies $9.4 \mathrm{kcal} / \mathrm{mol}$ above the dihydrogen complex at the $\operatorname{CCSD}(\mathrm{T})$ level. Moreover, the experimental trend on the stabilities is well reproduced by our calculations. The dihydrogen complex was found more stable than the dihydride only for the Cp/dppe set of ligands. ${ }^{6}$, 10, 33-35 We have also checked whether solvation affects the dihydrogen/dihydride relative stabilities by calculating the energy difference between the dihydrogen and dihydride forms of $\mathbf{2}$ in dicloromethane. The gas phase energy difference (4.9 $\mathrm{kcal} / \mathrm{mol}$ in favor of the dihydrogen complex) is only slightly decreased to $4.5 \mathrm{kcal} / \mathrm{mol}$ in $\mathrm{CH}_{2} \mathrm{Cl}_{2}$. Therefore, solvation plays a very minor role in this equilibrium. On the contrary, the equilibrium is strongly influenced by the $\mathrm{Cp}$ and phosphine substituents. The introduction of the methyl substituents in the $\mathrm{Cp}$ ring favors the dihydride, reversing the stabilities. The preference for the dihydride isomer is considerably enhanced by the presence of the isopropyl substituents in the phosphine. As the classical dihydride is the thermodynamic product of the protonation of the $\mathrm{Cp} * \mathrm{Fe}(\mathrm{dppe}) \mathrm{H}$ complex, ${ }^{6,10,11}$ we expect that it must be more stable than the related nonclassical dihydrogen complex. However, the non-classical dihydrogen complex is the most stable isomer for all of the models except when the computation is carried out on the real complex $\left[\mathrm{Cp} * \mathrm{Fe}(\mathrm{dppe})(\mathrm{H})_{2}\right]^{+}$. It is clear that in our case model systems cannot account for the experimental trends on the relative stability of the two isomers. 


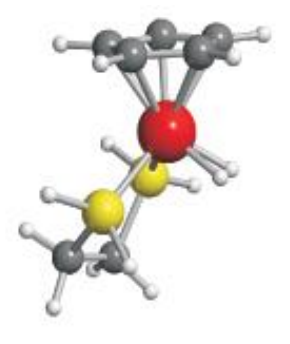

$1 \mathrm{c}$

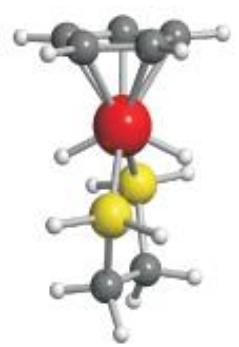

$1 \mathbf{t}$

Figure 3. Optimized geometries of the dihydrogen (left) and of the dihydride (right) isomers of $\left[\mathrm{CpFe}(\mathrm{dhpe}) \mathrm{H}_{2}\right]^{+}, \mathbf{1}$.

Table 2. Relative QM energies (in $\mathrm{kcal} / \mathrm{mol}, \mathrm{QM} / \mathrm{MM}$ values in parentheses) of the dihydride complexes, with respect to the corresponding dihydrogen isomer.

\begin{tabular}{cc}
\hline Complex & $\Delta \mathbf{E}$ \\
\hline$\left[\mathrm{CpFe}(\text { dhpe }) \mathrm{H}_{2}\right]^{+}, \mathbf{1}$ & 6.6 \\
{$\left[\mathrm{Cp} * \mathrm{Fe}(\text { dhpe }) \mathrm{H}_{2}\right]^{+}, \mathbf{2}$} & $4.9(5.9)^{\mathrm{a}}$ \\
{$\left[\mathrm{CpFe}(\text { dppe }) \mathrm{H}_{2}\right]^{+}, \mathbf{3}$} & $1.4(5.7)^{\mathrm{b}}$ \\
{$\left[\mathrm{Cp} \mathrm{p}^{*} \mathrm{Fe}(\text { dppe }) \mathrm{H}_{2}\right]^{+}, \mathbf{4}$} & $-3.9(0.1)^{\mathrm{b}}$ \\
{$\left[\mathrm{CpFe}(\text { dippe }) \mathrm{H}_{2}\right]^{+}, \mathbf{5}$} & $-3.6(0.9)^{\mathrm{c}}$ \\
{$\left[\mathrm{Cp} * \mathrm{Fe}(\text { dippe }) \mathrm{H}_{2}\right]^{+}, \mathbf{6}$} & $-8.6(-6.2)^{\mathrm{c}}$
\end{tabular}

The methyl groups of the $\mathrm{Cp}^{*}$ ligand are in the MM part. ${ }^{\mathrm{b}}$ The phenyl substituents of the dppe ligand are in the MM part. ${ }^{\mathrm{c}}$ The isopropyl substituents of the dippe ligand are in the MM part.

The substituents tune the relative stability of the dihydrogen and dihydride forms, and thus the ability of the metal fragment to break the H-H bond, by a combination of electronic and steric effects. We will apply a simple analysis already used on other systems to separate and quantify both contributions on the relative energies of the two isomers. ${ }^{36-38}$ To this aim, we have carried out additional QM/MM computations. The approach relies on two basic assumptions: 1) the full QM calculation on the whole system describes correctly the experimental behavior, and thus includes both electronic and steric contributions; 2) the QM/MM calculation describes only the steric effects of the groups included in the MM part, leaving out their electronic effects. From 
the small model $\left[\mathrm{CpFe}(\mathrm{dhpe}) \mathrm{H}_{2}\right]^{+}$, the substituents have been added in order to build up the real complexes, but in these QM/MM calculations they have been introduced at the molecular mechanics level (MM). By this scheme, only the steric contributions of the substituent are responsible of the changes in the relative stability of the two isomers.

The relative energy between the two isomers computed with the $\left[\mathrm{CpFe}(\mathrm{dhpe}) \mathrm{H}_{2}\right]^{+}$model is the reference. No substituents are present, neither on the $\mathrm{C}_{5}$ ring nor on the phosphine ligand, and the dihydrogen is $6.6 \mathrm{kcal} / \mathrm{mol}$ more stable than the dihydride. This value is reduced to 4.9 $\mathrm{kcal} / \mathrm{mol}$ when performing a full $\mathrm{QM}$ calculation of the $\left[\mathrm{Cp} * \mathrm{Fe}(\mathrm{dhpe}) \mathrm{H}_{2}\right]$ system 2, whereas a QM/MM calculation of the same system with the methyl substituents of the $\mathrm{Cp}^{*}$ considered only at the MM level gives the dihydrogen $5.9 \mathrm{kcal} / \mathrm{mol}$ more stable than the dihydride. The total contribution of the methyls is thus $1.7 \mathrm{kcal} / \mathrm{mol}$, of which 0.7 are attributed to the steric effect. Afterwards, the electronic effects of the methyl groups $(1.0 \mathrm{kcal} / \mathrm{mol})$ can be estimated by subtracting $(1.7-0.7)$ the steric effect from the total contribution. Of course, the electronic effect could also be evaluated directly as the difference $(5.9-4.9)$ between the relative QM and QM/MM energies reported in Table 2, with an identical result. The same scheme can be applied to the phenyl and isopropyl substituents. The results are summarized in Figure 4.

From $\left[\mathrm{CpFe}(\mathrm{dhpe}) \mathrm{H}_{2}\right]^{+}$(1) to $\left[\mathrm{Cp} * \mathrm{Fe}(\mathrm{dhpe}) \mathrm{H}_{2}\right]^{+}$(2) both the electronic and the steric effects are quite small and are in the same order of magnitude. However, the effect of the phenyl groups $\left(\left[\left(\mathrm{CpFe}(\mathrm{dhpe}) \mathrm{H}_{2}\right]^{+}(\mathbf{1}) \text { to }\left[\mathrm{CpFe}(\mathrm{dppe}) \mathrm{H}_{2}\right)\right]^{+}(\mathbf{3})\right)$ is more pronounced. The dihydride isomer is stabilized about $6.0 \mathrm{kcal} / \mathrm{mol}$, but this energy is not enough to reverse the thermodynamic preference for the dihydrogen. The extra-stabilization is mainly due to electronic effects, the steric effects being not relevant. When we compare the relative energies of the real systems containing the bulky phosphines and the $\mathrm{Cp}^{*}$ ligand, a stronger influence of the $\mathrm{Cp}^{*}$ methyl groups can be appreciated: $5.3 \mathrm{kcal} / \mathrm{mol}$ and $5.0 \mathrm{kcal} / \mathrm{mol}$ for the dppe and dippe phosphines, respectively. In both cases the substitution of $\mathrm{Cp}$ by $\mathrm{Cp}^{*}$ favors the dihydride complex. Assuming that the electronic effect of the methyls will be similar in the three cases, stabilizing the dihydride about $1.0 \mathrm{kcal} / \mathrm{mol}$, it is evident that steric factors of the ring substituents work in favor of the dihydride in the real complexes. Phenyl and isopropyl substituents have a major influence in the thermodynamic preference for the dihydride isomer. Changing the $\mathrm{H}$ model substituents by phenyls in the Cp* containing complexes ( 2 vs 4 ) favors the dihydride by $8.8 \mathrm{kcal} / \mathrm{mol}$, with a similar contribution of electronic and steric effects. The influence of the 
isopropyls ( 2 vs 6 ) in favoring the dihydride is even higher ( $13.5 \mathrm{kcal} / \mathrm{mol})$, although in this case the weight of the steric effects is the main cause for the extra stabilization of the dihydride isomer. The branched isopropyl groups have a more important steric hindrance than the planar phenyl groups rendering the dihydride the favored isomer, even with the Cp ligand ( 1 vs $\mathbf{5})$.

At a first glance, it could seem surprising that the coordination number increase associated with the dihydrogen $\rightarrow$ dihydride interconverson could be favored on steric grounds. However, the destabilizing steric interactions are not developed between the piano-stool legs, but rather between the phosphine substituents and the $\mathrm{C}_{5}$ ring. They are signalled by the notable increase in the $\left[\mathrm{C}_{5}\right.$ ring(centroid) $]-\mathrm{Fe}-\left[\mathrm{P}_{2}\right.$ (centroid) $](\alpha)$ angle on going from the dihydrogen $\left(\alpha\right.$ about $\left.150^{\circ}\right)$ to the dihydride structures ( $\alpha$ about $180^{\circ}$ ), see Supporting Information. In a thorough study of the $\eta^{2}$-dihydrogen complexes of ruthenium, it was already pointed out that the interaction of phosphine substituents with the $\mathrm{Cp}$ or $\mathrm{Cp}^{*}$ ring may be significant in determining the position of the dihydrogen $\rightarrow$ dihydride equilibrium. ${ }^{3}$ Our study fully confirms this hypothesis and quantifies the magnitude of such interaction.

The electronic effects also stabilize the dihydride isomer. The largest effect is found with the phenyl groups. The role of the phenyl substituents is particularly important in the preferential stabilization of the isomer with the highest oxidation state. The omission of the phenyl substituents in the model complexes is the main reason of the poor results they give for the dihydrogen/dihydride relative energies.

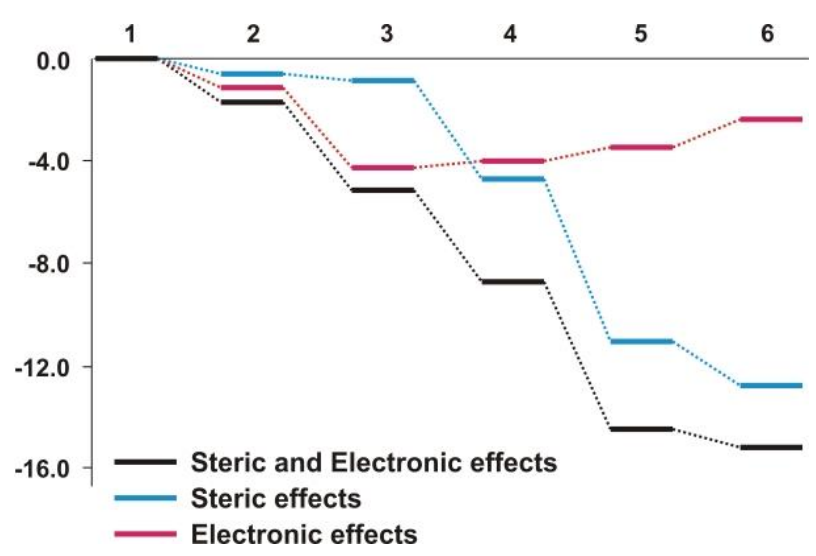

Figure 4. Substituent steric and electronic effects on the stabilization of the classical dihydride isomer for the complexes drawn in Scheme 3. 


\section{Computational study of the Dihydrogen $\rightarrow$ Dihydride Isomerization.}

We now turn to the analysis of the isomerization mechanism. As mentioned in the introduction, several mechanisms have been suggested for the isomerization of the related dihydrogen Ru derivatives: ${ }^{3,9,39,40}$ 1) a direct intramolecular rearrangement through a trigonal bipyramidal transition state; 2) a dissociative process with the partial or total phosphine ligand decoordination; 3) a relay of the migrating hydride via the cyclopentadienyl ligand; 4) a deprotonation of the cis isomer followed by protonation of the metal at the trans position. The first three possibilities are intramolecular processes while the latest involves a proton donor molecule. Since we have accumulated evidence, including the present study, that the isomerization rate of $\left[\mathrm{Cp} * \mathrm{Fe}(\mathrm{dppe}) \mathrm{H}_{2}\right]^{+}$is independent of the nature of the proton donor, ${ }^{6,10,11}$ only intramolecular mechanisms have been explored. In addition, the new experimental results shown in this paper set an experimental value to calibrate the highest enthalpy point along the computed reaction coordinate.

In order to keep the computational demands affordable, the study of the reaction mechanisms was performed at a full quantum mechanical level (QM) only for the $\left[\mathrm{CpFe}(\mathrm{dhpe}) \mathrm{H}_{2}\right]^{+}$and $\left[\mathrm{Cp} * \mathrm{Fe}(\mathrm{dhpe}) \mathrm{H}_{2}\right]^{+}$model complexes, and at the QM/MM level with the IMOMM method for the real $\left[\mathrm{Cp} * \mathrm{Fe}(\mathrm{dppe}) \mathrm{H}_{2}\right]^{+}$complex (with phenyl groups at the molecular mechanics level). Additional single point energy computations at the full QM level on the real [Cp* $\left.\mathrm{Fe}(\mathrm{dppe}) \mathrm{H}_{2}\right]^{+}$ complex were performed on the geometry of the intermediates and transition states located along the QM/MM potential energy surface (QM//IMOMM).

Direct Intramolecular Rearrangement. As discussed above, in these piano-stool compounds the cis-dihydrogen $\rightarrow$ trans-dihydride isomerization implies two processes: oxidative addition of $\mathrm{H}_{2}$ and structural rearrangement of the piano-stool legs. These two processes may proceed in one or two steps. The simple cleavage of the $\mathrm{H}-\mathrm{H}$ bond in the dihydrogen structure leads to a cis-dihydride. Although there are no reports of cis-dihydride $\left[\left(\mathrm{C}_{5} \mathrm{R}_{5}\right) \mathrm{FeH}_{2}(\mathrm{PP})\right]^{+}$ complexes, either isolated or spectroscopically detected, we considered also the possibility of a transient cis-dihydride intermediate. Starting from the dihydrogen complex and taking as a reaction coordinate the $\mathrm{H}-\mathrm{H}$ distance, we calculated the energy curve for the $\mathrm{H}-\mathrm{H}$ breaking. The energy was continuously increasing and no stationary point corresponding to a cis-dihydride intermediate could be located. Thus, the reaction appears to be taking place in a single step. 
Then, we explored the potential energy surface for the intramolecular rearrangement taking the $\mathrm{H}-\mathrm{Fe}-\mathrm{H}$ angle as the reaction coordinate. While the two hydride positions are symmetry equivalent in the starting dihydrogen complex, they become inequivalent in the transition state. They will be identified as the "fixed" $\left(\mathrm{H}_{\mathrm{f}}\right)$ and "migrating" $\left(\mathrm{H}_{\mathrm{m}}\right)$ positions, respectively The $\mathrm{H}_{\mathrm{f}}$ $\mathrm{Fe}-\mathrm{H}_{\mathrm{m}}$ angle must undergo a large change during the process: from $32^{\circ}$ in the dihydrogen complex to $131^{\circ}$ in the dihydride. Starting from the maximum of this monodimensional energy profile we were able to locate the transition state for the direct intramolecular rearrangement (TS dir). This presents a single imaginary frequency $\left(298 \mathrm{i} \mathrm{cm}^{-1}\right)$ with the opening of the $\mathrm{H}_{\mathrm{f}}-\mathrm{Fe}-\mathrm{H}_{\mathrm{m}}$ angle as the main component of its associated eigenvector. The mechanism of the process is illustrated in Figure 5 (right hand side), together with the structure of the $\mathbf{T S}_{\mathrm{dir}}$ for the $\left[\mathrm{Cp} * \mathrm{Fe}(\mathrm{dhpe}) \mathrm{H}_{2}\right]^{+}$system. The main geometric parameters of the $\mathbf{T} \mathbf{S}_{\mathbf{d i r}}$ for the $\mathrm{Cp}^{*}$-dhpe system are given in Table 3, while the full list of calculated frequencies as given as Supporting Information. Similar structural values, not reported for the sake of brevity, are obtained for the Cp-dhpe and $\mathrm{Cp}^{*}$-dppe systems. 


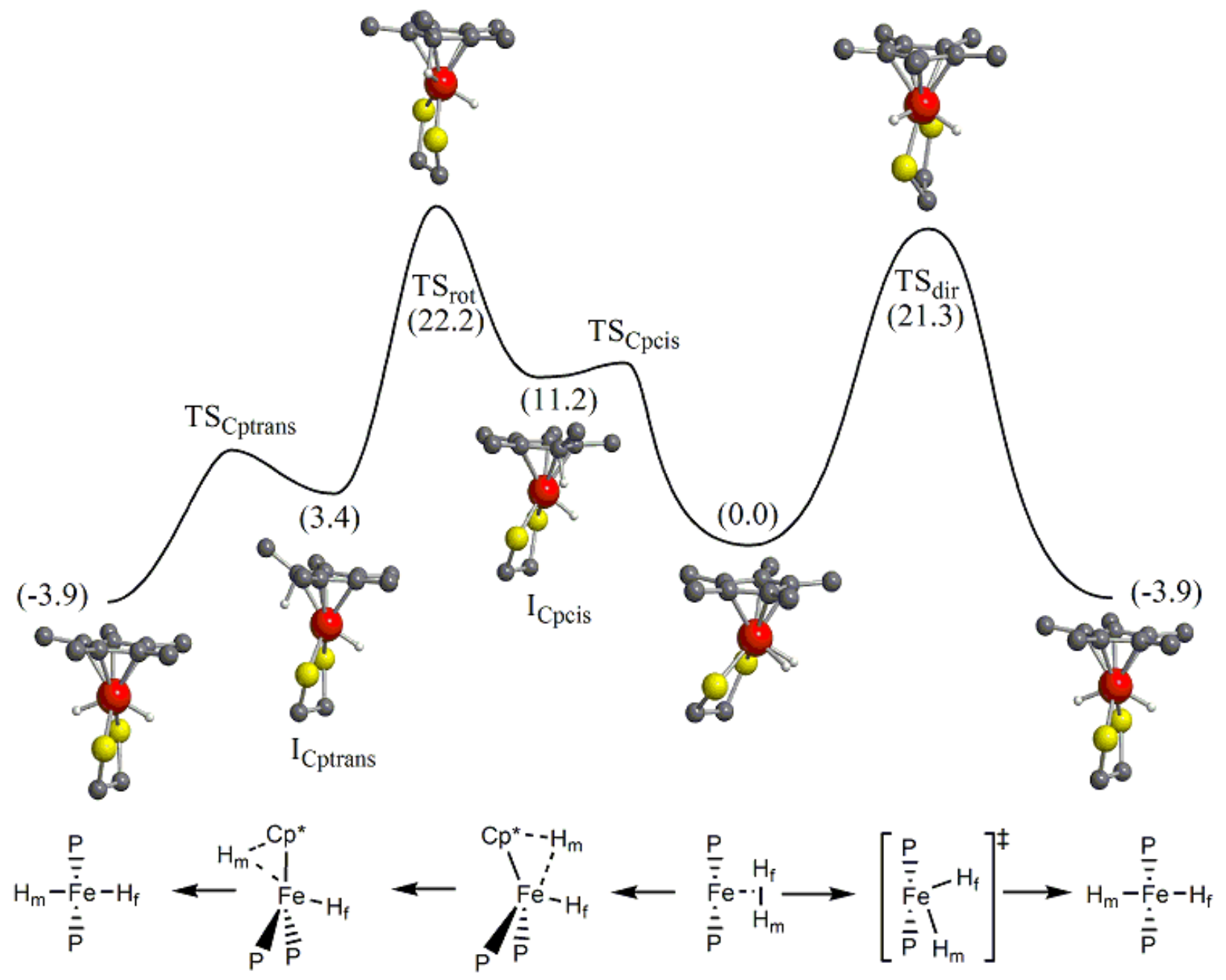

Figure 5. Direct (right) and "via $C p$ " (left) pathways for the cis-dihydrogen $\rightarrow$ transdihydride isomerization. The optimized geometries are shown for the $\left[\mathrm{Cp}^{*} \mathrm{Fe}(\mathrm{dhpe}) \mathrm{H}_{2}\right]^{+}$system (the $\mathrm{Cp}^{*}$ and dhpe $\mathrm{H}$ atoms have been omitted for sake of clarity) whereas the energies (in $\mathrm{kcal} / \mathrm{mol}$ ) correspond to the QM calculations on the QM/MM optimized $\left[\mathrm{Cp}^{*} \mathrm{Fe}(\mathrm{dppe}) \mathrm{H}_{2}\right]^{+}$system.

Table 3. Main geometrical parameters (distances in $\AA$ and angles in degrees) of the transition states for the two reported dihydrogen $\rightarrow$ dihydride interconversion mechanisms of $\left[\mathrm{Cp} * \mathrm{Fe}(\mathrm{dhpe}) \mathrm{H}_{2}\right]^{+}$. Values for the initial dihydrogen and the final dihydride complexes are also included.

2-c $\quad$ TS $_{\text {dir }} \quad$ TS $_{\text {rot }} \quad$ 2-t




\begin{tabular}{|c|c|c|c|c|}
\hline \multirow{2}{*}{ Fe-H } & 1.576 & 1.482 & 1.483 & 1.482 \\
\hline & 1.580 & 1.490 & 1.644 & 1.482 \\
\hline $\mathrm{H}_{\mathrm{f}-\mathrm{H}_{\mathrm{m}}}$ & 0.869 & 2.282 & 2.274 & 2.698 \\
\hline \multirow{2}{*}{ Fe-P } & 2.220 & 2.149 & 2.165 & 2.166 \\
\hline & 2.208 & 2.203 & 2.183 & 2.167 \\
\hline \multirow{2}{*}{$\mathrm{Fe}-\mathrm{C}(\mathrm{Cp})_{\text {range }}$} & 2.121 & 2.115 & 2.104 & 2.105 \\
\hline & 2.159 & 2.202 & 2.238 & 2.135 \\
\hline $\boldsymbol{\alpha}^{\mathrm{a}}$ & 144.8 & 158.9 & 162.3 & 179.3 \\
\hline $\mathbf{P}_{1}-\mathrm{Fe}-\mathrm{P}_{2}$ & 85.2 & 84.0 & 85.1 & 91.5 \\
\hline $\mathbf{H}_{\mathrm{f}-\mathrm{Fe}-\mathrm{H}_{\mathrm{m}}}$ & 32.0 & 100.3 & & 131.0 \\
\hline $\mathrm{Cp}^{*}-\mathrm{Fe}-\mathrm{H}_{\mathrm{f}}-\mathrm{H}_{\mathrm{m}}{ }^{\mathrm{b}}$ & 36.9 & 100.7 & & 179.7 \\
\hline $\mathrm{Cp}_{c}{ }^{*}-\mathrm{Fe}-\mathrm{P}_{1}-\mathrm{P}_{2}{ }^{\mathrm{b}}$ & 115.8 & 151.8 & & 178.8 \\
\hline $\mathrm{Cp}_{\mathrm{c}}{ }^{*}-\mathrm{Fe}-\mathrm{P}_{1}^{\mathrm{b}}$ & 126.0 & 153.6 & & 134.0 \\
\hline $\mathrm{Cp}_{\mathrm{c}}{ }^{*}-\mathrm{Fe}-\mathrm{P}_{2}^{\mathrm{b}}$ & 128.0 & 119.0 & & 134.0 \\
\hline
\end{tabular}

The transition state has a dihydride nature. The $\mathrm{H}-\mathrm{H}$ bond appears totally broken as reflected by the long $\mathrm{H}-\mathrm{H}$ separation, whereas the two $\mathrm{Fe}-\mathrm{H}$ bonds are already formed. Consequently, the oxidative addition process is already completed at the transition state level; the structure can be described as a Fe(IV) dihydride. Nevertheless, the $\alpha$ angle is closer to its initial value in the dihydrogen complex than to the $180^{\circ}$ value in the final dihydride. The phosphine ligand is also experiencing a significant repositioning. The dihedral angle formed by the $\mathrm{C}_{5}$-ring centroid, the iron atom, and the two $\mathrm{P}$ atoms takes a midway value (about $150^{\circ}$ ) between the $115^{\circ}$ in the dihydrogen and the $180^{\circ}$ in the trans-dihydride. The movement of the phosphine ligand can also be appreciated from the two $\mathrm{Cp}_{\mathrm{c}}{ }^{*}$-Fe-P angles. These are close to each other both in the starting dihydrogen and final dihydride complexes, and the values do not change much going from one to the other $\left(126^{\circ}\right.$ and $128^{\circ}$ for the dihydrogen complex, $134^{\circ}$ and $134^{\circ}$ for the dihydride complex). However, one angle is opened to $150^{\circ}$, whereas the other one is closed to $120^{\circ}$, in the transition state. This illustrates the swing of the entire diphosphine ligand toward one side of the 
molecule, which is necessary to allow passage of one hydride ligand from the side, in order to move from the front to the back of the metal center.

Given that both the transition state and the final trans-dihydride are four-legged piano stool complexes, they can be analyzed in relation to the mechanisms invoked for the $\mathrm{CpMo}(\mathrm{CO})_{2} \mathrm{LR}$ cis-trans interconversion. ${ }^{3,41}$ Within this model, the two trigonal-bipyramidal-like transition states presented in Scheme 4 can be envisaged. The geometric parameters of the transition states are in closer agreement with a structure of type $\mathbf{B}$, describing a movement in which one of the phosphine arms has moved down to allow the migration of the hydride ligand towards its final position. The generation of a four-legged piano-stool product with a transoid disposition of the $\mathrm{E}$ and $\mathrm{H}$ ligands resulting from the oxidative addition of a $\mathrm{E}-\mathrm{H}$ bond by a $\left(\mathrm{C}_{5} \mathrm{R}_{5}\right) \mathrm{ML}_{2}$ fragment is a relatively common result, not well explained yet. A transition state closely related to TSdir has been reported for the cis-trans isomerization of a hydrido-aryl complex of rhenium. ${ }^{42}$ It could be also at work for the oxidative addition of an alkyne C-H bond to yield a trans-alkynyl-hydride. ${ }^{37}$

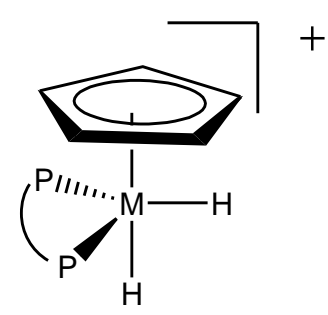

A

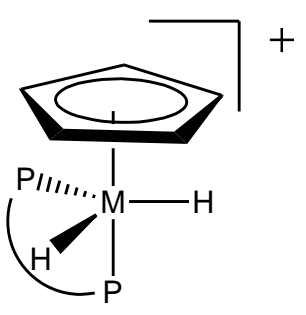

B

\section{Scheme 4}

The transition state $\mathbf{T} S_{\text {dir }}$ lies 30.1 and $28.9 \mathrm{kcal} / \mathrm{mol}$ above the dihydrogen for the $\left[\mathrm{CpFe}(\mathrm{dhpe}) \mathrm{H}_{2}\right]^{+}$and $\left[\mathrm{Cp} * \mathrm{Fe}(\mathrm{dhpe}) \mathrm{H}_{2}\right]^{+}$, respectively (Table 4). In these model systems the effect of the $\mathrm{Cp}$ methyl substituents is to decrease slightly the potential energy barrier. We have also computed the enthalpy and free energy of activation, namely $\Delta \mathrm{H}^{*}=27.1 \mathrm{kcal} / \mathrm{mol}$ and $\Delta \mathrm{G}^{*}=$ $30.7 \mathrm{kcal} / \mathrm{mol}$ for $\left[\mathrm{Cp} * \mathrm{Fe}(\mathrm{dhpe}) \mathrm{H}_{2}\right]^{+}$at $\mathrm{T}=298.15 \mathrm{~K}$. The small, almost zero activation entropy $\left(\Delta \mathrm{S}^{\ddagger}=-3.9 \mathrm{eu}\right)$ is not inconsistent with the small value observed in this work for the Fe complex (vide supra), and with the experimentally reported $\Delta \mathrm{S}^{\ddagger}(-3.3 \pm 0.7 \mathrm{eu})$ in related ruthenium complexes. ${ }^{3}$ As already found for the dihydrogen-dihydride equilibrium, the energy barrier of the 
rearrangement is only slightly affected by solvent effects. The computed barrier in $\mathrm{CH}_{2} \mathrm{Cl}_{2}$ for the $\left[\mathrm{Cp} * \mathrm{Fe}(\mathrm{dhpe}) \mathrm{H}_{2}\right]^{+}$system is $28.6 \mathrm{kcal} / \mathrm{mol}$, very close to the gas phase value $(28.9 \mathrm{kcal} / \mathrm{mol})$.

Table 4. Relative Energies $(\Delta \mathrm{E}, \mathrm{kcal} / \mathrm{mol})$ of the Species Involved in the Two Mechanisms.

\begin{tabular}{|c|c|c|c|c|c|c|c|c|}
\hline & Dihydrogen & TSCpcis & ICpcis & TSRot & $\mathbf{T S}_{\text {dir }}$ & ICptrans & TS Cptrans & Dihydride \\
\hline 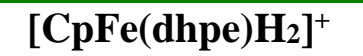 & 0.0 & & & & 30.1 & & & 6.6 \\
\hline$\left[\mathrm{Cp} * \mathrm{Fe}(\mathrm{dhpe}) \mathrm{H}_{2}\right]^{+}$ & 0.0 & 15.3 & 14.9 & 30.0 & 28.9 & 11.5 & 12.5 & 4.9 \\
\hline$\left[\mathrm{Cp} * \mathrm{Fe}(\mathrm{dppe}) \mathrm{H}_{2}\right]^{+\mathrm{a}}$ & 0.0 & & 12.1 & 23.9 & 24.5 & 5.9 & & 0.1 \\
\hline$\left[\mathrm{Cp} * \mathrm{Fe}(\mathrm{dppe}) \mathrm{H}_{2}\right]^{+b}$ & 0.0 & & 11.2 & 22.2 & 21.3 & 3.4 & & -3.9 \\
\hline
\end{tabular}

${ }^{a} \mathrm{QM} / \mathrm{MM}$ calculation with the phenyl groups in the MM part.

${ }^{\mathrm{b}}$ Full QM calculation at the QM/MM optimized geometries.

As reported for the relative stabilities of the dihydrogen and dihydride complexes, the effect of the substituents (electronic and steric) are also major on the transition state energy. The stabilization found for the $\mathrm{Cp}^{*}$ transition state is similar to that found for the minima, in agreement with the dihydride nature of the transition state. The same trend could by inferred for the phenyl effects, and this is indeed the case. The potential energy barrier for the real system $\left[\mathrm{Cp} * \mathrm{Fe}(\mathrm{dppe}) \mathrm{H}_{2}\right]^{+}$, with the phenyl groups described at the QM/MM level, is computed as 24.5 $\mathrm{kcal} / \mathrm{mol}$, and full QM energy computations at the fixed QM/MM minima and transition state further lower the energy barrier to $21.3 \mathrm{kcal} / \mathrm{mol}$. Thus, the effect of the phenyl substituents is to considerably decrease the isomerization barrier. The calculated barrier is very close to the experimental value of $21.6 \pm 0.8 \mathrm{kcal} \mathrm{mol}^{-1}$ (see above) and is also close to the barrier of the related isomerization of the $\left[\mathrm{Cp} * \mathrm{Ru}(\operatorname{dippe})\left(\mathrm{H}_{2}\right)\right]^{+}$complex. $^{9}$

Phosphine dissociation mechanism. We have also considered a dissociative isomerization mechanism, in which one of the phosphorus atoms in the $\left[\mathrm{Cp} * \mathrm{Fe}(\mathrm{dhpe})\left(\mathrm{H}_{2}\right)\right]^{+}$ complex dissociates from the metal, yielding an unsaturated intermediate where the diphosphine acts as a monodentate ligand. The oxidative addition would subsequently take place in this intermediate. However, the non-classical dihydrogen complex with one phosphine arm fully 
decoordinated is $30.0 \mathrm{kcal} \mathrm{mol}^{-1}$ above the saturated dihydrogen complex. This high Fe-P binding energy value led us to discard this mechanism for the systems under study.

Isomerization through the cyclopentadienyl ring. Some examples of hydrogen migration involving the metal center and the cyclopentadienyl ring can be found in the literature for iron compounds. Examples are provided by $\left[\eta^{4}-\mathrm{C}_{5} \mathrm{H}_{5}(\right.$ exo-D $\left.)\right] \mathrm{Fe}(\mathrm{CO})_{3},{ }^{43} \mathrm{Fe}(\mathrm{CO})_{3}\left(\eta^{4}-\right.$ $\left.\mathrm{C}_{6} \mathrm{H}_{7} \mathrm{Ph}\right)^{44}$ and $\left(\eta^{5}-\mathrm{C}_{5} \mathrm{H}_{5}\right) \mathrm{FeH}\left(\right.$ triphos) (triphos $\left.=\mathrm{Ph}_{2} \mathrm{PCH}_{2} \mathrm{CH}_{2} \mathrm{PPh}_{-} \mathrm{CH}_{2} \mathrm{CH}_{2} \mathrm{PPh}_{2}\right){ }^{45}$ These isomerizations take place under more drastic conditions relative to the dihydrogen $\rightarrow$ dihydride interconversion examined here. In addition, this mechanism was briefly contemplated for the analogous Ru system by Chinn and Heinekey ${ }^{3}$ but considered unlikely on the basis of bond strength considerations. During the thorough exploration of the potential energy surface for the dihydrogen $\rightarrow$ dihydride rearrangement in the $\left[\mathrm{Cp} * \mathrm{Fe}(\text { dhpe })\left(\mathrm{H}_{2}\right)\right]^{+}$system, we discovered the existence of low lying intermediates with a protonated $\mathrm{C}_{5}$ ring. This finding prompted us to fully explore the "via Cp" mechanism.

This mechanism appears as a multistep pathway in which the $\mathrm{H}_{\mathrm{m}}$ atom migrates from the cis to the trans position via a successive series of $\mathrm{H}$-jumps from and to the metal, together with a rotation of the protonated $\mathrm{C}_{5}$ ring. The mechanism of the process is illustrated in Figure 5 (left hand side), along with the structure of all intermediates for the $\left[\mathrm{Cp} * \mathrm{Fe}(\mathrm{dhpe}) \mathrm{H}_{2}\right]^{+}$system. The most relevant geometrical parameters of the $\mathbf{T S}$ rot (one imaginary frequency with $87 \mathrm{i} \mathrm{cm}^{-1}$ ) for the $\mathrm{Cp}^{*}$-dhpe system are given in Table 3, while the full list of calculated frequencies as given as Supporting Information. The two intermediates, ICpcis and ICptrans, are formally unsaturated, 16electron diene $\mathrm{Fe}(\mathrm{II})$ complexes, $\left[\left(\eta^{4}-\mathrm{C}_{5} \mathrm{Me}_{5} \mathrm{H}\right) \mathrm{Fe}(\mathrm{dppe}) \mathrm{H}\right]^{+}$. However, they are stabilized by an agnostic interaction established by the newly created $\sigma \mathrm{C}-\mathrm{H}$ bond and the Fe center, which keeps the $\mathrm{C}_{5}$ ring essentially planar. The $\mathrm{C}-\mathrm{H}$ and Fe-H distances $\left(1.248 \AA\right.$ and $1.661 \AA$ in $\mathbf{I}_{\mathbf{C} p c i s} ; 1.216$ $\AA$ and $1.757 \AA$ in ICptrans) confirm the presence of this interaction. The H-H bond is completely broken in ICpcis $(\mathrm{H}-\mathrm{H}=2.005 \AA)$. In the rotation transition state TSrot the proton is midway between the two positions. The $\mathrm{H}-\mathrm{H}$ distance is almost constant along the rotation. The TSrot also presents a $\sigma \mathrm{C}-\mathrm{H}$ agostic interaction with the Fe center $(\mathrm{C}-\mathrm{H}=1.179 \AA$; $\mathrm{Fe}-\mathrm{H}=1.483 \AA)$. The transition states $\mathbf{T} \mathbf{S}_{\mathbf{C} \text { pis }}$ and $\mathbf{T} \mathbf{S}_{\mathbf{C p t r a n s}}$ have geometries very near thaose of the corresponding intermediates, ICpcis and ICptrans, respectively. The optimized geometries of all stationary points are available as Supporting Information. 
This first step can be viewed as an intramolecular heterolytic splitting of the $\mathrm{H}-\mathrm{H}$ bond of the dihydrogen ligand. In cationic complexes, the $\eta^{2}-\mathrm{H}_{2}$ ligand can be acidic enough to protonate a basic cis ligand, see Scheme 5, ${ }^{46}$ whereas the basic properties of a $\mathrm{Cp} *$ ligand are well known. We have searched the related ring-protonated intermediate for the simpler $\mathrm{Cp}$ model complex, but this search was unsuccessful. All our attempts to obtain such species reverted to the dyhdrogen complex. Evidently, the simpler $\mathrm{Cp}$ ligand is not basic enough for this system to be protonated by the dihydrogen. We must point out that, for those $\mathrm{CpFe}$ complexes where the hydrogen migration from the metal center to the cyclopentadienyl ring has been experimentally observed, this process occurs under more drastic conditions. In terms of the currently examined mechanism, replacing $\mathrm{Cp}$ by $\mathrm{Cp}^{*}$ should facilitate the migration, making it possible under milder conditions.

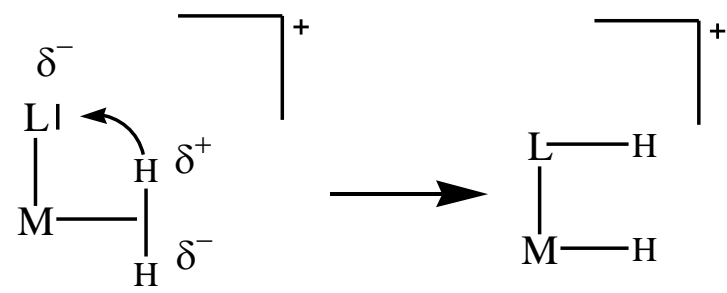

\section{Scheme 5}

The relative energies of the intermediates and transition states for the "via Cp" mechanism for the $\left[\mathrm{Cp} * \mathrm{Fe}(\mathrm{dhpe}) \mathrm{H}_{2}\right]^{+}$and $\left[\mathrm{Cp}^{*} \mathrm{Fe}(\mathrm{dppe}) \mathrm{H}_{2}\right]^{+}$systems are given in Table 4 . In the model system, the ICpcis intermediate lies $14.9 \mathrm{kcal} / \mathrm{mol}$ above the dihydrogen and the transition state than connects both is $0.4 \mathrm{kcal} / \mathrm{mol}$ above the intermediate. The trans-Cp* protonated complex is $3.4 \mathrm{kcal} / \mathrm{mol}$ more stable than the cis-protonated derivative. The transition state for the rotation of the protonated ring is found $30.0 \mathrm{kcal} / \mathrm{mol}$ above the initial dihydrogen complex in the gas phase and $30.8 \mathrm{kcal} / \mathrm{mol}$ in $\mathrm{CH}_{2} \mathrm{Cl}_{2}$. The energy barrier for the $\mathrm{Cp}^{*}$ rotation is 15.1 $\mathrm{kcal} / \mathrm{mol}$. The presence of the strong agostic bond, which is preserved along the rotation, is the main reason for this high value for a $\mathrm{Cp}^{*}$ rotational process. Therefore, the rate-determining step of the "via Cp" mechanism is the rotation of the protonated $\mathrm{Cp}^{*}$. The computed activation enthalpy and free energy are $\Delta \mathrm{H}^{\ddagger}=29.2 \mathrm{kcal} / \mathrm{mol}$ and $\Delta \mathrm{G}^{\ddagger}=30.7 \mathrm{kcal} / \mathrm{mol}$. This intramolecular mechanism also implies a small negative activation entropy $\left(\Delta S^{\dot{5}}=-5.0\right.$ eu $)$. In the gas phase the 
energy barriers of the "direct" and "via Cp" mechanisms for the dihydrogen $\rightarrow$ trans-dihydride interconversion in the $\left[\mathrm{Cp} * \mathrm{Fe}(\mathrm{dhpe}) \mathrm{H}_{2}\right]^{+}$model system are very similar (about $30 \mathrm{kcal} / \mathrm{mol}$ ). Dichloromethane slightly favors the direct mechanism, increasing the difference between both barriers from 1.1 to $2.2 \mathrm{kcal} / \mathrm{mol}$. Next, we examine how the presence of the phenyl substituents in the real system affects this result.

For the $\left[\mathrm{Cp} * \mathrm{Fe}(\mathrm{dppe}) \mathrm{H}_{2}\right]^{+}$complex, we have not been able to find the transition states

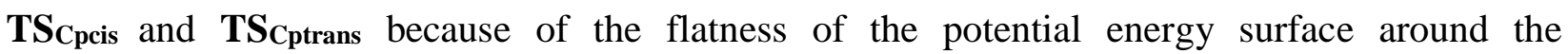
intermediates. The main effect of the phenyl groups is to stabilize all the species involved in the mechanism with respect the dihydrogen complex (see Table 4). Given that the phenyl groups are described at the MM level, the explanation for this behavior should be in the steric effects. On the basis of the results presented above on the relative stabilities of the dihydrogen and dihydride forms, the main reason for this behavior could be attributed to a destabilization of the dihydrogen complex by the steric interaction between phenyl and methyl groups. Very close values of the energy barriers for the "direct" and "via Cp" mechanisms are found also for the real system at the QM/MM level: $24.5 \mathrm{kcal} / \mathrm{mol}$ (“direct") and $23.9 \mathrm{kcal} / \mathrm{mol}$ ("via Cp").

In order to introduce the electronic effects of the phenyl substituents, we have performed full $\mathrm{QM}$ computations at the fixed $\mathrm{QM} / \mathrm{MM}$ structures of the optimized intermediates and transition state of the $\left[\mathrm{Cp} * \mathrm{Fe}(\mathrm{dppe}) \mathrm{H}_{2}\right]^{+}$system. The relative energies of all the intermediates and

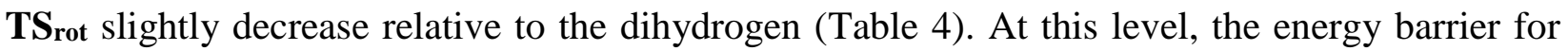
the "via Cp" pathway remains again close to that computed for the "direct" pathway and to the experimentally determined values. Thus, the possibility of a dihydrogen $\rightarrow$ dihydride interconversion via hydrogen migration to the $\mathrm{Cp}$ * ring and involving an heterolytic $\mathrm{H}-\mathrm{H}$ bond breaking appears as a feasible and competing pathway, together with the expected direct oxidative addition mechanism in these cationic iron half-sandwich complexes. Therefore, the computational work carried out so far does not allow a clear-cut distinction of the two alternative mechanisms. For this reason, we have decided to carry out a more detailed analysis of the kinetic isotope effect. 


\section{Isomerization kinetics of $\left[\mathrm{Cp} * \mathrm{Fe}(\mathrm{dppe})\left(\eta^{2}-\mathrm{HD}\right)\right]^{+}$}

The isomerization kinetics starting from the hydride complex $\mathrm{Cp}^{*} \mathrm{Fe}(\mathrm{dppe}) \mathrm{H}$ and the deuterated trifluoroacetic acid, $\mathrm{CF}_{3} \mathrm{COOD}$, in a 1:1 ratio provided additional information on the KIE. We carried out this experiment hoping to be able to measure the isomerization rate constant of the pure $\eta^{2}$-HD complex $\left(k_{\mathrm{HD}}\right)$, and compare this with the result of the rate constants given in Table 1 for the $\eta^{2}-\mathrm{H}_{2}\left(k_{\mathrm{HH}}\right)$ and $\eta^{2}-\mathrm{D}_{2}\left(k_{\mathrm{DD}}\right)$ complexes. As it turns out, the outcome of this experiment was more complex and interesting than expected, because the nonclassical species obtained by low-temperature protonation establishes a rapid equilibrium with the mixture of the other two isotopomers. This means that, although the proton transfer to the hydride site is effectively quantitative when using a strong acid such as $\mathrm{CF}_{3} \mathrm{COOD}$, the process is still subject to rapid reversibility, generating both $\mathrm{CF}_{3} \mathrm{COOH}$ and $\mathrm{Cp} * \mathrm{Fe}(\mathrm{dppe}) \mathrm{D}$ that further lead to the other two nonclassical complexes as shown in Scheme 6. Therefore, subsequent isomerization yields all three classical products.

However, useful kinetics information could still be obtained from this experiment, because: (i) the equilibration between the three nonclassical isotopomers according to the equilibrium shown in Equation 1 is much more rapid than the isomerization rate; (ii) the isomerization is irreversible; (iii) the classical dihydride products of the isomerization process do not scramble the hydride ligands. The latter statement was verified by an independent experiment, where a sample of $\left[\mathrm{Cp} * \mathrm{Fe}(\mathrm{dppe})(\mathrm{H})_{2}\right]^{+}$was generated and then treated with an equivalent amount of $\mathrm{CF}_{3} \mathrm{COOD}$. No deuterium incorporation occurred over $2 \mathrm{~h}$ at $273 \mathrm{~K}$ (the isomerization process is extensive over this timescale, as can be seen in Figure 1).

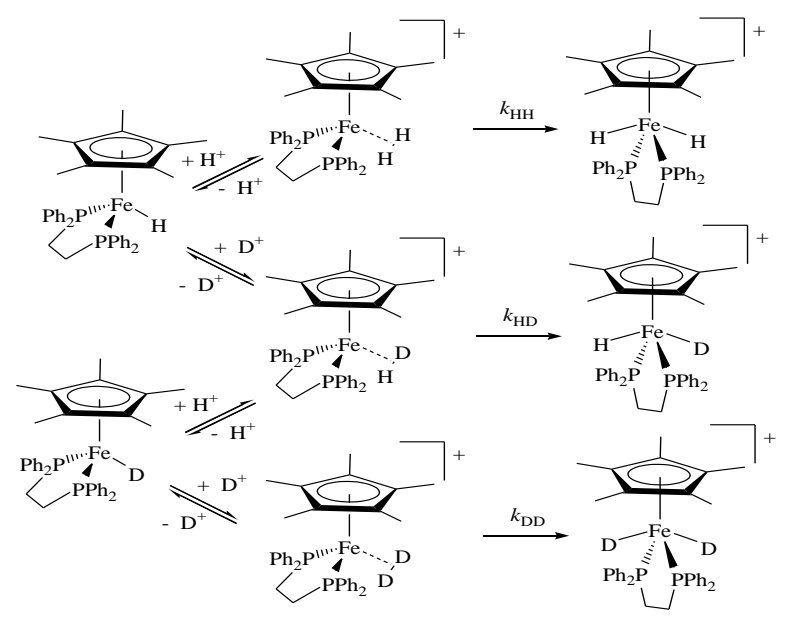




\section{Scheme 6}

\section{Equation 1}

$\left[\mathrm{Cp} * \mathrm{Fe}(\mathrm{dppe})\left(\eta^{2}-\mathrm{H}_{2}\right)\right]^{+}+\left[\mathrm{Cp} * \mathrm{Fe}(\mathrm{dppe})\left(\eta^{2}-\mathrm{D}_{2}\right)\right]^{+} \rightleftarrows 2\left[\mathrm{Cp} * \mathrm{Fe}(\mathrm{dppe})\left(\eta^{2}-\mathrm{HD}\right)\right]^{+}$

The information on the individual concentration of the three non-classical and the three classical species from a kinetics run carried out at $0^{\circ} \mathrm{C}$, starting with ca. equimolar amounts of $\mathrm{Cp} * \mathrm{FeH}(\mathrm{dppe})$ and $\mathrm{CF}_{3} \mathrm{COOD}$, was obtained by integration of the inverse gated doubly decoupled ${ }^{31} \mathrm{P}\left\{{ }^{1} \mathrm{H},{ }^{2} \mathrm{H}\right\}$ NMR resonances. An example of a recorded spectrum is shown in Figure 6. The double decoupling from proton and deuterium is essential to generate sufficiently sharp resonances and allow a satisfactory deconvolution of the individual components, especially for the non-classical isotopomers. The inverse gated procedure, together with long relaxation times and the use of a small pulse angle (see details in the Experimental Section), allowed to remove or at least minimize the distortion of the integrated intensities caused by the nuclear Overhauser effect and by an incomplete magnetisation recovery. Visual inspection of Figure 6 shows that the classical structure experiences a much greater isotope shift than the nonclassical one. This is quite expected, since the isotope effect in the former is transmitted from the hydride ligands to the detected ${ }^{31} \mathrm{P}$ nucleus through stronger Fe-H covalent bonds.

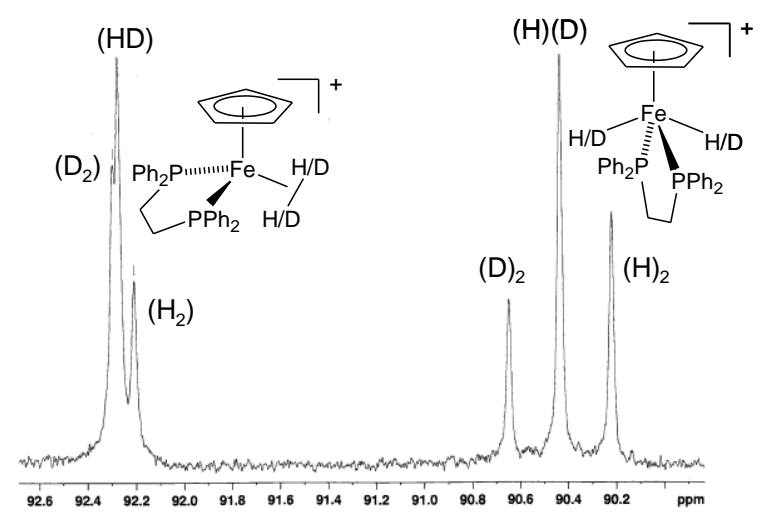

Figure 6. Example of a ${ }^{31} \mathrm{P}$ NMR spectrum obtained during the kinetic run of the isomerization experiment starting from $\mathrm{Cp} * \mathrm{Fe} \mathrm{H}(\mathrm{dppe})+\mathrm{CF}_{3} \mathrm{COOD}(1: 1)$ at $0^{\circ} \mathrm{C}$ in $\mathrm{CD}_{2} \mathrm{Cl}_{2}$. 
The evolution of the signal intensities is shown in Figure 7. The presence of a KIE is already quite evident from a qualitative analysis of the experimental data. In fact, the concentration of the $\eta^{2}-\mathrm{H}_{2}$ complex is always below that of the $\eta^{2}-\mathrm{D}_{2}$ complex, whereas the classical dihydride product always has a greater concentration than that the dideuteride product. Fitting the calculated decays of the three nonclassical species and the calculated growth of the three classical species to the experimental data gave the solid lines indicated in Figure 7 for the optimized rate constant values reported in Table 1 (run 8). The details of the data analysis, which required the numerical integration of the coupled differential equations and a global least squared fitting procedure, is available as Supporting Information. Note that the optimized value for $k_{\mathrm{HH}}$ is identical within the experimental error to that independently (and more directly) obtained from the $\mathrm{CF}_{3} \mathrm{COOH}$ protonation (Table 1 , run 6). In addition, the optimized value of $k_{\mathrm{DD}}$ is slightly lower than that obtained directly from the $\mathrm{CF}_{3} \mathrm{COOD}$ protonation of the deuteride sample (Table 1 , run 7), which must be considered an upper estimate as discussed above.
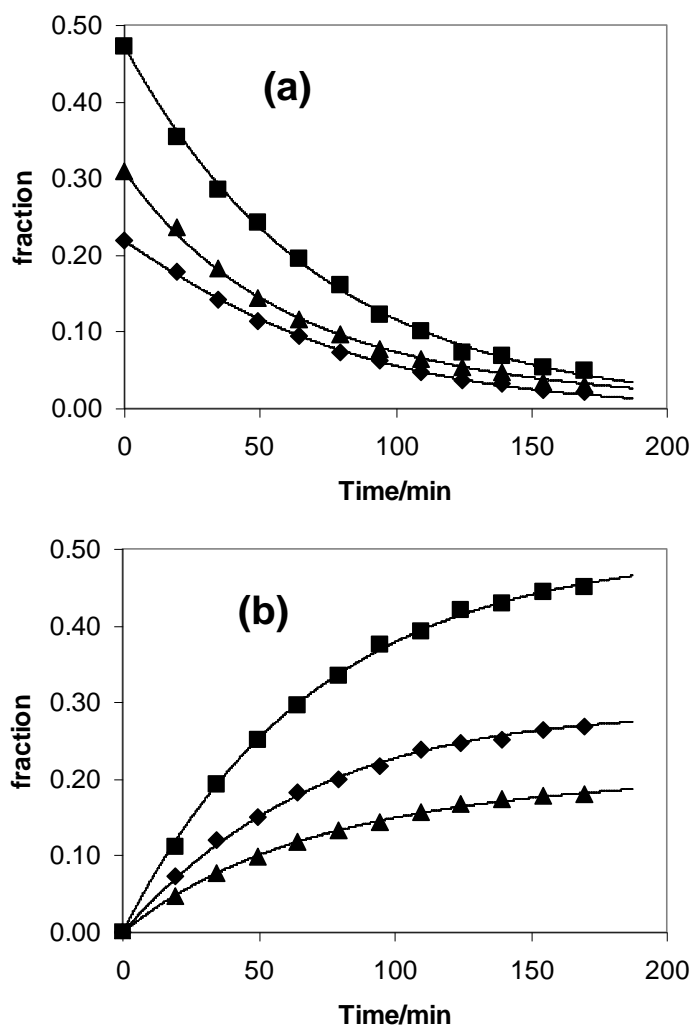

Figure 7. Evolution of the concentrations of (a) nonclassical and (b) classical complexes during the isomerization process following the reaction of $\mathrm{Cp}^{*} \mathrm{Fe}(\mathrm{dppe}) \mathrm{H}$ with $\mathrm{CF}_{3} \mathrm{COOD}$ at 
$0^{\circ} \mathrm{C}$ in $\mathrm{CD}_{2} \mathrm{Cl}_{2}$. Diamonds: dihydride; squares: monohydride monodeuteride; triangles: dideuteride. The solid lines are the best fit on the basis of the kinetic model as outlined in the text and in Supporting Information.

The data analysis (see Supporting Information) used the assumptions that the mixture of the three nonclassical isotopomers is instantaneously equilibrated by virtue of Equation 1, with an equilibrium constant taken as the average calculated from the experimental data $(K=3.3 \pm 0.3)$. Note that this value is significantly different from that expected for a statistical distribution without isotope effect $(K=4)$. When the fitting procedure was repeated by manually altering this $K$ value to 4 or to other values, the obtained residual was greater, confirming the significance of this deviation. Such observations prove that besides the kinetic isotope effect affecting the dihydrogen-dihydride isomerization, there is an additional equilibrium isotope effect (EIE) on the isotope redistribution equilibrium among the three non-classical species. The reason for this EIE will be analyzed in the next section.

From the results in Table 1 (run 8), we can derive $k_{\mathrm{HH}} / k_{\mathrm{HD}}=1.24 \pm 0.01$ and $k_{\mathrm{HD}} / k_{\mathrm{DD}}=$ $1.58 \pm 0.01$. Isotope effects have been previously reported for the oxidative addition of $\mathrm{H}_{2}$ to transition metals, but only for reactions between a metal complex and free $\mathrm{H}_{2}$, to the best of our knowledge. Furthermore, they only relate to the addition of $\mathrm{H}_{2}$ vs. $\mathrm{D}_{2}$. Examples $\left(k_{\mathrm{H}} / k_{\mathrm{D}}\right.$ in parentheses) are the additions to $\mathrm{Fe}(\mathrm{CO})_{4}\left(1.1 \pm 0.1\right.$ at $\left.24{ }^{\circ} \mathrm{C}\right),{ }^{47}$ to $\operatorname{Ir}\left(\mathrm{PPh}_{3}\right)_{2}(\mathrm{CO}) \mathrm{Cl}(1.09$ at 25 $\left.{ }^{\circ} \mathrm{C}\right),{ }^{48,} 49$ to $\left[\mathrm{Rh}\left(\mathrm{PPh}_{3}\right)_{2} \mathrm{Cl}\right]\left(1.5\right.$ at $\left.23{ }^{\circ} \mathrm{C}\right),{ }^{50}$ to $\left[\mathrm{Cr}(\mathrm{CO})_{5}\left(\mathrm{C}_{6} \mathrm{H}_{12}\right)\right]\left(1.9\right.$ at $\left.23{ }^{\circ} \mathrm{C}\right),{ }^{51}$ and to $\left[\mathrm{W}\left(\mathrm{PMe}_{3}\right)_{3} \mathrm{I}_{2}\right]\left(1.2 \pm 0.2\right.$ at $\left.60{ }^{\circ} \mathrm{C}\right),{ }^{52}$ While the oxidative addition process may take place in a single step, a local energy minimum for an intermediate dihydrogen complex may also occur. In the latter case, when the slow step is the intramolecular rearrangement of the dihydrogen ligand, the observed isotope effect results from the combination of an EIE for the $\mathrm{H}_{2}$ coordination step and a KIE for the rearrangement. The $\mathrm{H}_{2}$ coordination equilibrium constant has been measured for a number of systems and is always characterized by an inverse EIE. Examples (with the $K_{\mathrm{H}} / K_{\mathrm{D}}$ in parentheses $)$ are $\left[\operatorname{Ir}\left(\mathrm{PCy}_{3}\right)_{2} \mathrm{HCl}_{2}\right]\left(0.50\right.$ at $\left.-13{ }^{\circ} \mathrm{C}\right),{ }^{53}\left[\operatorname{Ir}\left(\mathrm{P}_{\mathrm{B}} \mathrm{Bu}_{2} \mathrm{Me}\right)_{2} \mathrm{H}_{2} \mathrm{Cl}\right](0.37$ at -13 $\left.{ }^{\circ} \mathrm{C}\right),{ }^{54}\left[\mathrm{Os}\left(\mathrm{PiPr}_{3}\right)_{2}(\mathrm{CO})(\mathrm{Cl}) \mathrm{H}\right]\left(0.35\right.$ at $\left.85^{\circ} \mathrm{C}\right),{ }^{55}\left[\mathrm{Cr}(\mathrm{CO})_{3}\left(\mathrm{PCy}_{3}\right)_{2}\right]\left(0.65 \pm 0.15\right.$ at $\left.22{ }^{\circ} \mathrm{C}\right),{ }^{56}$ and $\left[\mathrm{W}\left(\mathrm{PMe}_{3}\right)_{4} \mathrm{I}_{2}\right]\left(0.63 \pm 0.05\right.$ at $\left.60{ }^{\circ} \mathrm{C}\right) .{ }^{52}$ Thus, a greater normal KIE for the isomerization process would be necessary to yield an observed normal KIE for the oxidative addition. Our determined $k_{\mathrm{HH}} / k_{\mathrm{DD}}$ value is $1.96 \pm 0.02$ at $273 \mathrm{~K}$, i.e. comparable to the highest reported value for an 
oxidative addition process, namely 1.9 for $\left[\mathrm{Cr}(\mathrm{CO})_{5}\left(\mathrm{C}_{6} \mathrm{H}_{12}\right)\right]{ }^{51}$ The present report appears to be the first direct investigation of the KIE for the rearrangement process of a dihydrogen intermediate to the final dihydride product and the first complete analysis encompassing the $\mathrm{H}_{2}$, $\mathrm{HD}$ and $\mathrm{D}_{2}$ isotopomers. Note, however, that the rearrangement does not consist of a simple $\mathrm{H}-\mathrm{H}$ bond breaking completed by the formation of the two $\mathrm{M}-\mathrm{H}$ bonds with little change in the rest of the coordination sphere, as it occurs in the majority of the other cases. A cis to trans rearrangement also takes place. Thus, the current results should not be extrapolated in general.

We can conclude that the isomerization process from $\left[\mathrm{Cp} * \mathrm{Fe}(\mathrm{dppe})\left(\eta^{2}-\mathrm{H}_{2}\right)\right]^{+}$to $\left[\mathrm{Cp} * \mathrm{Fe}(\mathrm{dppe}) \mathrm{H}_{2}\right]^{+}$has a small isotope effect, and that this is not symmetric relative to the two hydride ligands. This is not surprising, since the two hydride ligands are inequivalent in the rearrangement process (one migrates to the new position and the second one remains on the starting site). Both KIE's and the EIE will now be analyzed from a theoretical point of view, in terms of the two mechanistic pathways that were found energetically compatible with the measured activation enthalpy.

\section{Theoretical Analysis of the Equilibrium Isotope Effect.}

On the basis of the energy-optimized structure of the non-classical model complex $\left[\mathrm{Cp} * \mathrm{Fe}(\mathrm{dhpe})\left(\eta^{2}-\mathrm{H}_{2}\right)\right]^{+}$, i.e. system 2 , frequency calculations were run for the (HD) and $\left(\mathrm{D}_{2}\right)$ analogues. For the sake of clarity, the three isotopomers have been named $\mathbf{2}-\mathbf{H}_{2}$ (non-deuterated), 2-HD (monodeuterated) and 2-D2 (dideuterated). The EIE can be obtained directly from the calculated $\Delta \mathrm{G}$ of the isotope redistribution equilibrium (see thermochemical data in the Supporting Information). This is obtained from a statistical mechanics treatment that uses unscaled normal mode frequencies. The resulting value of the equilibrium constant for Equation 1 is 3.81. The slight disagreement with the experiment is expected, given the various approximations used by the calculation.

From the knowledge of the individual frequencies, the equilibrium constant may also be calculated through the classical Bigeleisen-Mayer treatment, where the constant is given by the expression in Equation 2. For the definition of the MMI (mass moment of inertia), EXC (excitations of vibrational energy levels), and ZPE (zero point vibrational energy) terms, see the Supporting Information and the literature. ${ }^{57,58}$ The factor of 4 takes into account the doubled concentration of the (HD) species in the equilibrium expression. The advantage of the 
Bigeleisen-Mayer treatment is to pinpoint the isotope sensitive modes that are mostly responsible for the observed effect. Related analyses have been previously reported for the secondary isotope effects in the coordination of $\mathrm{C}_{2} \mathrm{H}_{4}$ vs. $\mathrm{C}_{2} \mathrm{D}_{4}$ to the $\mathrm{Os}_{2}(\mathrm{CO})_{8}$ moiety, ${ }^{59}$ and for the primary isotope effects in the $\mathrm{H}_{2} / \mathrm{D}_{2}, \mathrm{CH}_{4} / \mathrm{CH}_{3} \mathrm{D}$ and $\mathrm{CH}_{4} / \mathrm{CD}_{4}$ oxidative additions to trans$\operatorname{Ir}\left(\mathrm{PR}_{3}\right)_{2}(\mathrm{CO}) \mathrm{X},{ }^{60}$ in the $\mathrm{H}_{2} / \mathrm{D}_{2}$ coordination to $\mathrm{W}(\mathrm{CO})_{3}(\mathrm{PCy})_{2},{ }^{56}$ and in the $\mathrm{H}_{2} / \mathrm{D}_{2} / \mathrm{T}_{2}$ coordination and oxidative addition to $\mathrm{W}(\mathrm{CO})_{5}{ }^{61}$ The isotopic redistribution between $\left(\mathrm{H}_{2}\right)$, (HD) and $\left(\mathrm{D}_{2}\right)$ complexes has never been analyzed to the best of our knowledge.

\section{Equation 2}

$K=4(\mathrm{MMI})(\mathrm{EXC})(\mathrm{ZPE})$

This type of analysis was carried out for our system on the basis of the selected, most isotope-sensitive frequencies, reported in Table 5 (no scaling factors have been used). Only these normal modes are sensitive to the isotope nature and contribute significantly to the EIE. A full list of vibrational frequencies is provided in the Supporting Information section. The calculated $K$ value is 3.30 at $273 \mathrm{~K}$, in agreement with the experimental value. As Table 5 shows, the EIE is dominated by the zero point energy term and the most significant contribution to the reduction of $K$ from the statistical value of 4 is given by the $v(\mathrm{H}-\mathrm{H})$ vibration. However, the contribution of the other isotope-sensitive modes cannot be neglected.

Table 5. Frequency analysis of the Equilibrium Isotope Effect for the isotope redistribution equilibrium in complex $\left[\mathrm{Cp} * \mathrm{Fe}(\mathrm{dhpe})\left(\eta^{2}-\mathrm{XY}\right)\right]^{+}(\mathbf{2}-\mathrm{XY})(\mathrm{X}, \mathrm{Y}=\mathrm{H}, \mathrm{D})$ at $273 \mathrm{~K}$.

\begin{tabular}{ccclcccc} 
& \multicolumn{1}{c}{ 2- $_{\mathbf{2}}-1$} & & \multicolumn{1}{c}{ Assignment } & MMI & EXC & ZPE & $K$ \\
\hline 2762.7 & 2423.5 & 1956.3 & $v(\mathrm{H}-\mathrm{H})$ & 1.09 & 0.95 & 0.71 & 2.94 \\
1810.3 & 1561.0 & 1283.9 & $v_{\text {as }}(\mathrm{Fe}-\mathrm{H})$ & 1.05 & 0.98 & 0.93 & 3.84 \\
1096.9 & 903.1 & 785.6 & $v_{\text {sym }}(\mathrm{Fe}-\mathrm{H})$ & 0.95 & 1.03 & 1.22 & 4.78 \\
680.4 & 651.5 & 512.9 & $\delta\left(\mathrm{Fe}-\mathrm{H}_{2}\right)_{\text {out-of-plane }}$ & 1.22 & 1.00 & 0.75 & 3.65 \\
585.5 & 533.2 & 534.6 & $\delta\left(\mathrm{Fe}-\mathrm{H}_{2}\right)_{\text {in-plane }}$ & 0.91 & 1.00 & 1.15 & 4.19 \\
468.1 & 370.6 & 359.4 & $\tau\left(\mathrm{Fe}-\mathrm{H}_{2}\right)$ & 0.82 & 1.00 & 1.26 & 4.10
\end{tabular}




\section{Kinetic Isotope Effect on the Dihydrogen-Dihydride Isomerization.}

Analogous frequency calculations were run on the isotopomers of the two transition states corresponding to the two mechanisms found compatible with the experimental activation barrier. We must also consider that the symmetry of the $\mathrm{H}_{2}$ ligand is broken on going from the initial nonclassical system to the transition state. While the two hydride positions are symmetry equivalent in the starting dihydrogen complex, they become inequivalent in the transition state. They will be identified as the "fixed" $\left(\mathrm{H}_{\mathrm{f}} / \mathrm{D}_{\mathrm{f}}\right)$ and "migrating" $\left(\mathrm{H}_{\mathrm{m}} / \mathrm{D}_{\mathrm{m}}\right)$ positions, respectively (see Figure 5). This implies that two pathways for each mechanism must be considered in the case of the monodeuterated species, depending on whether the migrating atom is $\mathrm{H}$ or D.

Like for the EIE analysis, the KIE can be derived directly from the calculated free energies, in this case the activation free energies. These are reported in Table 6 and the corresponding ZPVE and thermal enthalpy values are included in the Supporting Information. Clearly, the migration of $\mathrm{H}$ is favored over the migration of $\mathrm{D}$ in the mixed 2-HD species for the "direct" mechanism, whereas the reverse is true for the "via Cp" mechanism. The resulting calculated isotope effects are given in Table 7. The $\Delta \Delta \mathrm{G}^{\neq}$values for the two different transition states of the 2-HD systems $\left(\mathrm{H}_{\mathrm{m}} \mathrm{D}_{\mathrm{f}}\right.$ and $\left.\mathrm{D}_{\mathrm{m}} \mathrm{H}_{\mathrm{f}}\right)$ are small in each mechanism $\left(-0.117 \mathrm{kcal} \mathrm{mol}^{-1}\right.$ for $\mathbf{T} \mathbf{S}_{\text {dir }}$ and $0.264 \mathrm{kcal} \mathrm{mol}^{-1}$ for TS rot), allowing the calculation of $k\left(\mathrm{H}_{\mathrm{m}} \mathrm{D}_{\mathrm{f}}\right) / k\left(\mathrm{D}_{\mathrm{m}} \mathrm{H}_{\mathrm{f}}\right)=1.241$ for the "direct" and 0.615 for the "via Cp" mechanism. Thus, a considerable fraction of the HD sample will isomerize by the less favourable pathway $\left(\mathrm{H}_{\mathrm{m}} \mathrm{D}_{\mathrm{f}} / \mathrm{D}_{\mathrm{m}} \mathrm{H}_{\mathrm{f}}=55.4: 44.6\right.$ for the "direct" and 38.1:61.9 for the "via Cp" mechanism). The observed KIE must take this into account. Thus, the calculated effective rate of isomerization for the 2-HD species will be $k_{\mathrm{HD}}=0.554 k\left(\mathrm{H}_{\mathrm{m}} \mathrm{D}_{\mathrm{f}}\right)+$ $0.446 k\left(\mathrm{D}_{\mathrm{m}} \mathrm{H}_{\mathrm{f}}\right)$ for the "direct" pathway and $k_{\mathrm{HD}}=0.381 k\left(\mathrm{H}_{\mathrm{m}} \mathrm{D}_{\mathrm{f}}\right)+0.619 k\left(\mathrm{D}_{\mathrm{m}} \mathrm{H}_{\mathrm{f}}\right)$ for the "via Cp" pathway. This leads to the calculation of the following values for the KIE:
(a) Direct
(b) Via Cp
$k_{\mathrm{HH}} / k_{\mathrm{HD}}=1.428$
$k_{\mathrm{HH}} / k_{\mathrm{HD}}=0.924$
$k_{\mathrm{HD}} / k_{\mathrm{DD}}=1.547$
$k_{\mathrm{HD}} / k_{\mathrm{DD}}=1.147$ 
The computed values are in much better agreement with the experimental ones $(1.24 \pm 0.01$ and $1.58 \pm 0.01$, respectively) for the "direct" mechanism. This result must therefore be considered in strong support of the occurrence of the "direct" mechanism and against the "via Cp" mechanism.

Table 6. Calculated activation free energies in $\mathrm{kcal} \mathrm{mol}^{-1}$ (and relative $\Delta \Delta \mathrm{G}^{\neq}$values with respect to $\Delta \mathrm{G}^{\neq}(\mathrm{HH})$ in parentheses) for the "direct" and "via Cp" mechanisms at 273 $\mathrm{K}\left(\left[\mathrm{Cp} * \mathrm{Fe}(\mathrm{dhpe}) \mathrm{H}_{2}\right]^{+}\right.$model system $)$.

\begin{tabular}{lcccc}
\hline Mechanism & $\Delta \mathbf{G}^{\neq}(\mathbf{H H})$ & $\Delta \mathbf{G}^{\neq}\left(\mathbf{H}_{\mathbf{m}} \mathbf{D}_{\mathbf{f}}\right)$ & $\Delta \mathbf{G}^{\neq}\left(\mathbf{D}_{\mathbf{m}} \mathbf{H}_{\mathbf{f}}\right)$ & $\Delta \mathbf{G}^{\neq}(\mathbf{D D})$ \\
\hline Direct & 29.26 & 29.41 & 29.54 & 29.70 \\
& $(0.00)$ & $(0.15)$ & $(0.28)$ & $(0.44)$ \\
\multirow{2}{*}{ Via Cp } & 31.27 & 31.41 & 31.15 & 31.31 \\
& $(0.00)$ & $(0.14)$ & $(-0.12)$ & $(0.04)$ \\
\hline
\end{tabular}

Table 7. Frequency analysis of the Kinetic Isotope Effect for the irreversible isomerization of $\left[\mathrm{Cp} * \mathrm{Fe}(\mathrm{dhpe})\left(\eta^{2}-\mathrm{AB}\right)\right]^{+}$to $\left.\left[\mathrm{Cp}^{*} \mathrm{Fe}(\mathrm{dhpe})(\mathrm{A})(\mathrm{B})\right]^{+}(\mathrm{A}, \mathrm{B}=\mathrm{H}, \mathrm{D})\right)$ at $273 \mathrm{~K}$.

\begin{tabular}{|c|c|c|c|c|c|}
\hline $\mathbf{X} / \mathbf{Y}^{\mathbf{a}}$ & VP* & EXC* & $\mathbf{Z P E}^{*}$ & $k_{\mathrm{X}} / k_{\mathrm{Y}} \mathrm{b}$ & $k_{\mathrm{X}} / k_{\mathrm{Y}} \mathrm{c}$ \\
\hline \multicolumn{6}{|c|}{ (a) "direct" mechanism } \\
\hline HH/H $\mathbf{H}_{\mathrm{m}}$ & 0.938 & 1.050 & 1.313 & 1.304 & 1.299 \\
\hline HH/Dm $\mathbf{H}_{\mathbf{f}}$ & 0.753 & 1.126 & 1.380 & 1.619 & 1.536 \\
\hline $\mathbf{H}_{\mathrm{m}} \mathbf{D}_{\mathrm{f}} / \mathbf{D D}$ & 0.772 & 1.093 & 1.521 & 1.693 & 1.680 \\
\hline $\mathbf{D}_{\mathrm{m}} \mathbf{H}_{\mathrm{f}} / \mathbf{D D}$ & 0.961 & 1.019 & 1.447 & 1.364 & 1.421 \\
\hline \multicolumn{6}{|c|}{ (b) "via Cp" mechanism } \\
\hline HH/HmDf & 1.018 & 1.027 & 1.150 & 1.282 & 1.215 \\
\hline$H H / H_{m} D_{f}$ & 0.997 & 1.100 & 0.742 & 0.788 & 0.816 \\
\hline $\mathrm{H}_{\mathrm{m}} \mathrm{D}_{\mathrm{f}} / \mathrm{DD}$ & 1.018 & 1.068 & 0.824 & 0.826 & 0.897 \\
\hline $\mathrm{H}_{\mathrm{m}} \mathrm{D}_{\mathrm{f}} / \mathrm{DD}$ & 1.038 & 0.998 & 1.277 & 1.344 & 1.336 \\
\hline
\end{tabular}

aThe $m$ and f labels refer to the "moving" and "fixed" atoms involved in the rearrangement. ${ }^{\mathrm{b}}$ From the $\Delta \mathrm{G}^{*}$ analysis (see text). ${ }^{\mathrm{c}}$ From Equation 3 and the selected frequencies in Table 8 . 
Like for the EIE analysis, the kinetic isope effects can also be calculated by an extension of the Bigeleisen-Mayer method, ${ }^{58,62}$ the relevant relationship becoming that of Equation 3 . The expressions of the $\mathrm{VP}^{*}, \mathrm{EXC}^{*}$ and $\mathrm{ZPE}^{*}$ terms are based on the starting materials and transition states, rather than on the starting materials and products. They are again available in the Supporting Information and in the literature.

\section{Equation 3}

$$
\mathrm{KIE}=\frac{k_{X}}{k_{Y}}=\left(\mathrm{VP}^{*}\right)\left(\mathrm{EXC}^{*}\right)\left(\mathrm{ZPE}^{*}\right)
$$

Table 8 collects only those frequencies that are sensitive to the isotope nature and contribute significantly to the KIE. The full list of frequencies is available in the Supporting Information. The frequency analysis in this case is not as straightforward as for the EIE, especially for the "via Cp" mechanism, since the Fe-X/Y and X-Y stretching and bending motions are heavily mixed with other molecular motions in several normal modes. Only those normal modes having a major component from the Fe-X/Y bonds have been explicitly assigned in Table 8. The calculation of the various terms of Equation 3 leads to the values collected in Table 7. It can be seen that the $\mathrm{ZPE}^{*}$ term contributes the most, but the VP* term also gives an important contribution, especially for the "direct" mechanism when comparing different moving atoms $\left(\mathrm{H}_{\mathrm{m}} / \mathrm{D}_{\mathrm{m}}\right)$. This is mostly due to the $\left(\mathrm{v}^{*} \mathrm{X} / \mathrm{v}^{*} \mathrm{Y}\right)$ term contained in $\mathrm{VP}^{*}$ (ratio of the imaginary frequencies, see Supporting Information), because large changes at the level of the Fe$\mathrm{H}_{\mathrm{m}}$ and $\mathrm{H}_{\mathrm{f}}-\mathrm{H}_{\mathrm{m}}$ bonds occur around TSdir. On the other hand, the "via Cp" mechanism involves a transition state TSrot connecting two agostic intermediates and having itself a significant agostic interaction. The $\mathrm{C}-\mathrm{H}_{\mathrm{m}}$ and $\mathrm{Fe}-\mathrm{H}_{\mathrm{m}}$ bonds undergo little changes around TSrot, resulting in essentially isotope independent imaginary frequencies.

Table 8. Isotope-sensitive frequencies $\left(\mathrm{cm}^{-1}\right)$ for the transition states of the "direct" (TS $\left.\mathbf{\text { dir }}\right)$ and "via Cp" (TSrot) mechanisms.

(a) "direct" mechanism 


\begin{tabular}{ccccl} 
TS $_{\text {dir-H2 }}$ & TS $_{\text {dir-Hm }} \mathbf{D}_{\mathbf{f}}$ & $\mathbf{T S}_{\text {dir-D }} \mathbf{D}_{\mathbf{f}}$ & $\mathbf{T S}_{\text {dir-D2 }}$ & Assignment \\
\hline-298.3 & -296.8 & -227.2 & -226.6 & $v^{*}$ \\
507.5 & 601.2 & 507.1 & 598.8 & \\
536.5 & 523.6 & 536.3 & 522.6 & \\
587.0 & 593.8 & 586.8 & 593.7 & \\
591.7 & 568.5 & 589.0 & 567.3 & \\
654.5 & 466.1 & 651.2 & 465.1 & $\delta\left(\mathrm{Fe}-\mathrm{H}_{\mathrm{f}}\right)_{\text {in-plane }}$ \\
667.5 & 545.4 & 662.6 & 544.3 & \\
677.0 & 668.4 & 675.6 & 664.7 & \\
778.7 & 671.4 & 783.1 & 668.9 & \\
1025.3 & 1024.9 & 719.3 & 721.3 & $\delta\left(\mathrm{Fe}-\mathrm{H}_{\mathrm{m}}\right)_{\text {out-of-plane }}$ \\
1921.0 & 1369.7 & 1921.3 & 1369.0 & $v\left(\mathrm{Fe}-\mathrm{H}_{\mathrm{f}}\right)$ \\
2027.7 & 2027.5 & 1448.9 & 1449.4 & $v\left(\mathrm{Fe}-\mathrm{H}_{\mathrm{m}}\right)$
\end{tabular}

(b) "via Cp" mechanism

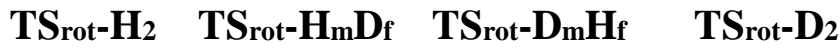

\begin{tabular}{lllll}
\hline-86.8 & -85.9 & -86.6 & -85.7 & $v^{*}$ \\
364.8 & 352.1 & 364.3 & 351.8 & \\
394.7 & 394.3 & 382.1 & 381.7 & \\
440.1 & 411.6 & 439.3 & 411.5 & \\
469.1 & 448.5 & 467.6 & 447.8 & \\
531.2 & 530.6 & 519.6 & 516.8 & \\
537.0 & 544.0 & 535.4 & 543.2 & \\
548.6 & 542.0 & 546.1 & 539.6 & \\
637.3 & 529.4 & 637.1 & 529.1 & $\delta\left(\mathrm{Fe}-\mathrm{H}_{\mathrm{f}}\right)$ \\
686.8 & 686.7 & 681.4 & 681.4 & \\
768.6 & 756.2 & 768.3 & 755.9 & \\
772.9 & 776.7 & 772.8 & 776.6 & \\
801.6 & 802.3 & 834.4 & 834.7 & \\
819.1 & 603.3 & 813.6 & 602.6 \\
823.7 & 822.4 & 821.3 & 817.5 \\
846.6 & 834.0 & 847.3 & 832.6
\end{tabular}




\begin{tabular}{rcccl}
929.9 & 929.9 & 699.9 & 700.0 & $\delta\left(\mathrm{Fe}-\mathrm{H}_{\mathrm{m}} \mathrm{C}\right)$ \\
983.2 & 982.9 & 1121.7 & 1121.7 & \\
1059.8 & 1059.7 & 998.1 & 997.7 & \\
1083.3 & 1083.2 & 1075.1 & 1075.0 & \\
1289.7 & 1289.7 & 906.9 & 906.6 & $v_{s y m}\left(\mathrm{Fe}-\mathrm{H}_{m} ; \mathrm{Fe}-\mathrm{C}\right)$ \\
1408.1 & 1408.3 & 1353.3 & 1353.3 & $v_{\text {as }}\left(\mathrm{Fe}-\mathrm{H}_{\mathrm{m}} ; \mathrm{Fe}-\mathrm{C}\right)$ \\
1924.1 & 1926.1 & 1386.2 & 1381.3 & $v_{\mathrm{sym}}\left(\mathrm{Fe}-\mathrm{H}_{\mathrm{m}} ; \mathrm{C}-\mathrm{H}_{\mathrm{m}}\right)$ \\
1952.3 & 1390.2 & 1950.4 & 1396.4 & $v\left(\mathrm{Fe}-\mathrm{H}_{\mathrm{f}}\right)$ \\
\hline
\end{tabular}

The corresponding KIE values are again listed in Table 7 . We can grossly attribute this difference to the variation of the chemical environment of the migrating atom, $H_{m} / D_{m}$, on going from the starting dihydrogen complex and the transition state. For the "direct" mechanism, the strong $\mathrm{H}-\mathrm{H}$ and the two weak Fe-H bonds (in-phase and out-of-phase stretching vibrations at 1096.9 and $1810.3 \mathrm{~cm}^{-1}$ for the $\mathbf{2}-\mathbf{H}_{2}$ species) are transformed into two stronger $\mathrm{Fe}-\mathrm{H}$ bonds, yielding stretching vibrations at 1921.0 (for $\mathrm{H}_{\mathrm{f}}$ ) and 2027.7 (for $\mathrm{H}_{\mathrm{m}}$ ) $\mathrm{cm}^{-1}$. However, the loss of the strong $\mathrm{H}-\mathrm{H}$ bond in the starting material $\left(v_{\mathrm{HH}}=2762.7 \mathrm{~cm}^{-1}\right)$ dominates, yielding a normal KIE. The fact that $\mathrm{KIE}(\mathrm{HH} / \mathrm{HD})$ is greater when the migrating atom is $\mathrm{D}$ (1.536, primary isotope effect) and lower when it is $\mathrm{H}(1.299$, secondary isotope effect) is not solely related to the bond stretching vibrations, since $v\left(F e-X_{m}\right)>v\left(F e-X_{f}\right)$ for both $X=H$ and $D$. Thus, the bending modes play a dominant role. The same argument rationalizes why KIE(HD/DD) is greater when the migrating atom is $\mathrm{H}$. For the "via Cp" mechanism, on the other hand, the two hydride ligands yield a relatively strong $\mathbf{F e}-\mathrm{H}_{\mathrm{f}}$ bond (its stretching vibration at $1952.3 \mathrm{~cm}^{-1}$ in $\mathbf{T S}$ rot is similar to that calculated in $\mathbf{T S}_{\text {dir }}$ ) and an agostic $\mathrm{Fe} \cdot \cdots \mathrm{H}_{\mathrm{m}}-\mathrm{C}$ moiety. The strength of the $\mathrm{C}-\mathrm{H}$ bond is reduced from that of a regular $\mathrm{C}-\mathrm{H}$ bond, but the combination of the $\mathrm{C}-\mathrm{H}_{\mathrm{m}}$ and $\mathrm{Fe} \cdot \mathrm{H}_{\mathrm{m}}$ vibrations, which are mixed with a Fe-C component, yields three relatively high frequency normal modes as shown in Scheme 7. The overall effect is a strengthening of the bonding environment for the $\mathrm{H}_{\mathrm{m}}$ atom and a weakening for the $\mathrm{H}_{\mathrm{f}}$ atom, leading to an inverse primary KIE (migrating D) and a normal secondary KIE (migrating $\mathrm{H}$ ). 

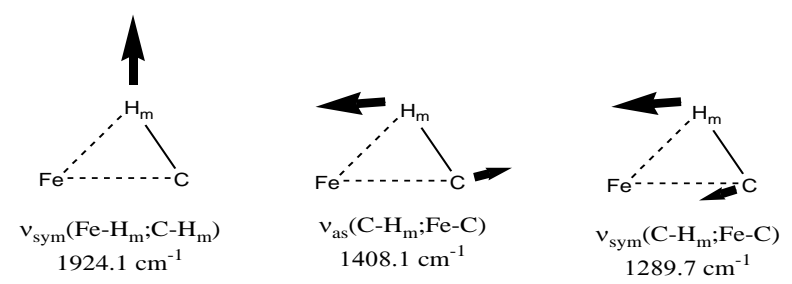

\section{Scheme 7}

\section{Conclusions}

We have reported here a detailed investigation of the irreversible isomerization process of the dihydrogen intermediate $\left[\mathrm{Cp} * \mathrm{Fe}(\mathrm{dppe})\left(\eta^{2}-\mathrm{H}_{2}\right)\right]^{+}$, obtained by low-temperature protonation of $\mathrm{Cp} * \mathrm{Fe}(\mathrm{dppe}) \mathrm{H}$, to the dihydride complex trans-[Cp*Fe(dppe $\left.(\mathrm{H})_{2}\right]^{+}$. The computational tool illustrates the need to include the steric and electronic effect of the $\mathrm{Cp}$ and diphosphine substituents, in order to quantitatively reproduce the relative stability of non classical and classical isomers and the activation barrier of the isomerization process. However, the calculations also indicated that two different pathways are likely candidates for the isomerization mechanism: a "direct" pathway $\left(\Delta \mathrm{E}^{\ddagger}=21.3 \mathrm{kcal} \mathrm{mol}^{-1}\right)$ and a "via $\mathrm{Cp}$ " pathway $\left(\Delta \mathrm{E}^{\ddagger}=22.2 \mathrm{kcal}\right.$ $\mathrm{mol}^{-1}$ ), never suggested previously, which involves cyclopentadiene intermediates (cf. $21.6 \pm 0.8$ $\mathrm{kcal} \mathrm{mol}^{-1}$ from the experiment). Sorting between these pathways was possible through the investigation of isotope effects. Generation of the $\left[\mathrm{Cp} * \mathrm{Fe}(\mathrm{dppe})\left(\eta^{2}-\mathrm{HD}\right)\right]^{+}$complex by protonation of $\mathrm{Cp} * \mathrm{Fe}($ dppe $) \mathrm{H}$ with $\mathrm{CF}_{3} \mathrm{COOD}$ results in a rapidly isotope redistribution equilibrium yielding complexes $\left[\mathrm{Cp} * \mathrm{Fe}(\mathrm{dppe})\left(\eta^{2}-\mathrm{H}_{2}\right)\right]^{+}$and $\left[\mathrm{Cp} * \mathrm{Fe}(\mathrm{dppe})\left(\eta^{2}-\mathrm{D}_{2}\right)\right]^{+}$; each of the three isotopomers isomerizes to the corresponding classical product with its own rate constant ( $k_{\mathrm{HH}}, k_{\mathrm{HD}}$ and $k_{\mathrm{DD}}$ ). The resulting KIE's at $273 \mathrm{~K}$ are $k_{\mathrm{HH}} / k_{\mathrm{HD}}=1.24 \pm 0.01$ and $k_{\mathrm{HD}} / k_{\mathrm{DD}}=$ $1.58 \pm 0.01$ (and consequently $k_{\mathrm{HH}} / k_{\mathrm{DD}}=1.96 \pm 0.02$ ). This type of isotope effect analysis, for a rearrangement process of a dihydrogen complex to the isomeric dihydride, and encompassing the three $\mathrm{H}_{2}, \mathrm{HD}$ and $\mathrm{D}_{2}$ isotopomers, is unprecedented to the best of our knowledge. The isotope redistribution EIE and the KIE's were also derived from the calculated normal mode frequencies of the dihydrogen isotopomers and the transition states. The computed values are in excellent 
agreement with the experimental values, but only for the "direct" isomerization mechanism, providing strong support in favor of this rearrangement pathway and against the "via Cp" pathway for this system. However, given the closeness of the calculated activation barriers, it seems reasonable to think that subtle modifications in the metallic system could favor a mechanism of the "via Cp" type.

Acknowledgements. We thank the European Commission through the HYDROCHEM program (contract HPRN-CT-2002-00176) for support of this work. Additional bilateral support (PICS, France-Russia) and National support from the CNRS (France), from the RFBR (05-0322001, 05-03-32415) and the Division of Chemistry and Material Sciences of RAS (Russia), and from MEC (project CTQ2005-09000-CO2-01; Spain) is also gratefully acknowledged. AL thanks the Generalitat de Catalunya for a Distinció per a la Promocio de la Recerca Universitària. NB thanks Russian Science Support Foundation for an individual grant. MB thanks the Spanish Ministerio de Educación y Ciencia for a post-doctoral fellowship.

Supporting Information Available: Details of the kinetic analysis for the $\mathrm{Cp} * \mathrm{Fe}(\mathrm{dppe}) \mathrm{H}+\mathrm{CF}_{3} \mathrm{COOD}$ reaction; optimized geometries (Cartesian coordinates) for the calculated species; calculated normal mode frequencies used for the equilibrium and kinetic isotope effect analyses (23 pages). This material is available free of charge via the Internet at http://pubs.acs.org.

\section{References}

$1 \quad$ Kubas, G. J., Metal Dihydrogen and $\sigma$-Bond Complexes. ed.; Kluwer Academic/Plenum Press: New York, 2001.

2 Parkin, G.; Bercaw, J. E., J. Chem. Soc., Chem. Commun. 1989, 255-257.

3 Chinn, M. S.; Heinekey, D. M., J. Am. Chem. Soc. 1990, 112, 5166-5175.

4 Jia, G.; Lough, A. J.; Morris, R. H., Organometallics 1992, 11, 161-171.

5 Papish, E. T.; Rix, F. C.; Spetseris, N.; Norton, J. R.; Williams, R. D., J. Am. Chem. Soc. 2000, 122, 12235-12242.

6 Hamon, J. R.; Hamon, P.; Toupet, L.; Costuas, K.; Saillard, J. Y., C. R. Chimie 2002, 5, 89-98.

7 Roger, C.; Hamon, P.; Toupet, L.; Rabaâ, H.; Saillard, J.-Y.; Hamon, J.-R.; Lapinte, C., Organometallics 1991, 10, 1045-1054. 
Ontko, A. C.; Houlis, R. J. F.; Schnabel, C.; Roddick, D. M.; Fong, T. P.; Lough, A. J.; Morris, R. H., Organometallics 1998, 17, 5467-5476.

De Los Ríos, I.; Jiménez-Tenorio, M.; Padilla, J.; Puerta, M. C.; Valerga, P., Organometallics 1996, 15, 4565-4574.

Belkova, N. V.; Revin, P. O.; Epstein, L. M.; Vorontsov, E. V.; Bakhmutov, V. I.;

Shubina, E. S.; Collange, E.; Poli, R., J. Am. Chem Soc. 2003, 125, 11106-11115.

Belkova, N. V., et al., Chem. Eur. J. 2005, 11, 873-888.

Frisch, M. J., et al., Gaussian 98. ed.; Gaussian, Inc.: Pittsburgh PA, 1998.

Perdew, J. P., Electronic Structure of Solids. In Ziesche, P.; Eschrig, H., Eds., Akademie Verlag: Berlin, 1991; 'Vol.' p^pp 11.

Perdew, J. P., Physical Review B-Condensed Matter 1986, 33, 8822-8824.

Becke, A. D., J. Chem. Phys. 1993, 98, 5648-5652.

Pople, J. A.; Krishnan, R.; Schlegel, H. B.; Binkley, J. S., Int. J. Quant. Chem. 1978, 14, 545-560.

Bartlett, R.; Purvis, G., Int. J. Quant. Chem. 1978, 14, 561-81.

Cizek, J., Adv. Chem. Phys. 1969, 14, 35.

Purvis, G. D.; Bartlett, R. J., J. Chem. Phys. 1982, 76, 1910-1918.

Scuseria, G. E.; Janssen, C. L.; Schaefer, H. F., J. Chem. Phys. 1988, 89, 7382-7387.

Scuseria, G. E.; Schaefer, H. F., J. Chem. Phys. 1989, 90, 3700-3703.

Pople, J. A.; Head-Gordon, M.; Raghavachari, K., J. Chem. Phys. 1987, 87, 59685975.

Wadt, W. R.; Hay, P. J., J. Chem. Phys. 1985, 82, 284-298.

Hay, P. J.; Wadt, W. R., J. Chem. Phys. 1985, 82, 270-283.

Höllwarth, A., et al., Chem. Phys. Lett. 1993, 208, $237-40$.

Hehre, W.; Ditchfie, R.; Pople, J., J. Chem. Phys. 1972, 56, 2257-2261.

Harihara, P.; Pople, J., Theor. Chim. Acta 1973, 28, 213-22.

Maseras, F.; Morokuma, K., J. Comput. Chem. 1995, 16, 1170-1179.

Allinger, N. L., mm3(92). ed.; Quantum Chemistry Program Exchange:

Bloomington, IN, 1992.

Frisch, M. J., et al., Gaussian 03, Revision C.02. ed.; Gaussian, Inc.: Wallingford CT, 2004.

Tomasi, J.; Persico, M., Chem. Rev. 1994, 94, 2027-2094.

Amovilli, C.; Barone, V.; Cammi, R.; Cancès, E.; Cossi, M.; Menucci, B.; Pomelli, C. S.; Tomasi, J., Adv. Quantum Chem. 1998, 32, 227-261.

Hamon, P.; Toupet, L.; Hamon, J.-R.; Lapinte, C., Organometallics 1992, 11, 14291431.

Jiménez-Tenorio, M.; Puerta, M. C.; Valerga, P., Organometallics 1994, 13, 33303337.

Jia, G.; Ng, W. S.; Yao, J.; Lau, C.-P.; Chen, Y., Organometallics 1996, 15, 5039-5045. Barea, G.; Maseras, F.; Jean, Y.; Lledós, A., Inorg. Chem. 1996, 35, 6401-6405.

Bustelo, E.; Carbo, J.; Lledós, A.; Mereiter, K.; Puerta, M.; Valerga, P., J. Am. Chem. Soc. 2003, 125, 3311-3321.

Maresca, O.; Maseras, F.; Lledós, A., New J. Chem. 2004, 28, 625-630. 
Cayuela, E.; Jalon, F. A.; Manzano, B. R.; Espino, G.; Weissensteiner, W.; Mereiter, K., J. Am. Chem. Soc. 2004, 126, 7049-7062.

Ryan, O. B.; Tilset, M., J. Am. Chem. Soc. 1991, 113, 9554-9561.

Faller, J. W.; Anderson, A. S., J. Am. Chem. Soc. 1970, 92, 5852-5860.

Clot, E.; Oelckers, B.; Klahn, A. H.; Eisenstein, O.; Perutz, R. N., J. Chem. Soc., Dalton Trans. 2003, 4065-4074.

Whitesides, T. H.; Shelly, J., J. Organomet. Chem. 1975, 92, 215-26.

Whitesides, T. H.; Neilan, J. P., J. Am. Chem. Soc. 1973, 95, 5811-13.

Davies, S. G.; Felkin, H.; Watts, O., J. Chem. Soc., Chem. Comm. 1980, 159-60.

Kubas, G. J., Adv. Inorg. Chem. 2004, 56, 127-177.

Wang, W.; Narducci, A. A.; House, P. G.; Weitz, E., J. Am. Chem. Soc. 1996, 118, 8654-8657.

Zhou, P.; Vitale, A. A.; San Filippo, J., Jr.; Saunders, W. H., Jr., J. Am. Chem. Soc. 1985, 107, 8049-54.

Abu-Hasanayn, F.; Goldman, A. S.; Krogh-Jespersen, K., J. Phys. Chem. 1993, 97, 5890-5896.

Wink, D. A.; Ford, P. C., J. Am. Chem. Soc. 1987, 109, 436-42.

Church, S. P.; Grevels, F.-W.; Hermann, H.; Schaffner, K., J. Chem. Soc., Chem. Comm. 1985, 30-2.

Hascall, T.; Rabinovich, D.; Murphy, V. J.; Beachy, M. D.; Friesner, R. A.; Parkin, G., J. Am. Chem. Soc. 1999, 121, 11402-11417.

Gusev, D. G.; Bakhmutov, V. I.; Grushin, V. V.; Vol'pin, M. E., Inorg. Chim. Acta 1990, 177, 115-20.

Hauger, B. E.; Gusev, D.; Caulton, K. G., J. Am. Chem. Soc. 1994, 116, 208-14.

Bakhmutov, V. I.; Bertrán, J.; Esteruelas, M. A.; Lledós, A.; Maseras, F.; Modrego, J.; Oro, L. A.; Sola, E., Chem. Eur. J. 1996, 2, 815-825.

Bender, B. R.; Kubas, G. J.; Jones, L. H.; Swanson, B. I.; Eckert, J.; Capps, K. B.;

Hoff, C. D., J. Am. Chem. Soc. 1997, 119, 9179-9190.

Bigeleisen, J.; Mayer, M. G., J. Chem. Phys. 1947, 15, 261-7.

Melander, L., Isotope effects on reaction rates. ed.; The Ronal Press Company: New York, 1960.

Bender, B. R., J. Am. Chem. Soc. 1995, 117, 11239-46.

Abu-Hasanayn, F.; Krogh-Jespersen, K.; Goldman, A. S., J. Am. Chem. Soc. 1993, 115, 8019-8023.

Janak, K.; Parkin, G., Organometallics 2003, 22, 4378-4380.

Bigeleisen, J., J. Chem. Phys. 1949, 17, 675-8. 


\section{Graphic for the Table of Contents}
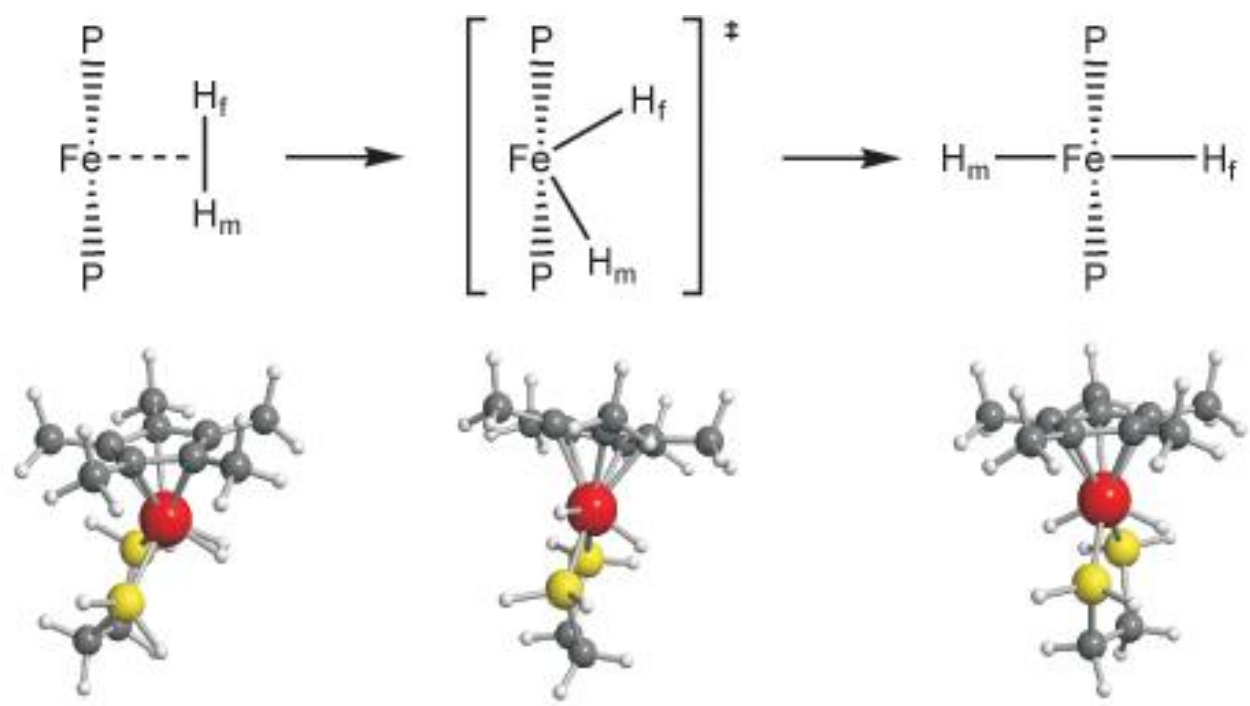

\section{Table of Content Synopsis}

The kinetic product of proton transfer to $\mathrm{Cp} * \mathrm{Fe}(\mathrm{dppe}) \mathrm{H}$, the dihydrogen complex $\left[\mathrm{Cp} * \mathrm{Fe}(\mathrm{dppe})\left(\mathrm{H}_{2}\right)\right]^{+}$, converts to the thermodynamic product, the dihydride $\left[\mathrm{Cp} * \mathrm{Fe}(\mathrm{dppe})(\mathrm{H})_{2}\right]^{+}$, by an internal rearrangement process. An alternative pathway involving a $\mathrm{Cp}^{*}$-assisted intramolecular proton migration is energetically competitive according to a DFT modeling study but may be discarded after comparing the measured and computed kinetic isotope effects. 